\title{
Structure and mechanism of human dual oxidase 1 complex
}

\author{
Jing-Xiang $\mathrm{Wu}^{1,2,3}$, Rui Liu ${ }^{1}$, Kangcheng Song ${ }^{1}$, and Lei Chen ${ }^{1,2,3 *}$
}

${ }^{1}$ State Key Laboratory of Membrane Biology, Institute of Molecular Medicine, Peking

University, Beijing Key Laboratory of Cardiometabolic Molecular Medicine, Beijing 100871, China

${ }^{2}$ Peking-Tsinghua Center for Life Sciences, Peking University, Beijing 100871, China

${ }^{3}$ Academy for Advanced Interdisciplinary Studies, Peking University, Beijing 100871, China

*Correspondence: Lei Chen, chenlei2016@pku.edu.cn 


\begin{abstract}
Dual oxidases (DUOXs) produce hydrogen peroxide by transferring electrons from intracellular NADPH to extracellular oxygen. They are involved in many crucial biological processes and human diseases, especially in thyroid diseases. DUOXs are protein complexes co-assembled from the catalytic DUOX subunits and the auxiliary DUOXA subunits and their activities are regulated by intracellular calcium concentrations. Here, we report the cryo-EM structures of human DUOX1-DUOXA1 complex in both high-calcium and low-calcium states. These structures reveal the DUOX1 complex is a symmetric 2:2 hetero-tetramer stabilized by extensive inter-subunit interactions. Substrate NADPH and cofactor FAD are sandwiched between transmembrane domain and the cytosolic dehydrogenase domain of DUOX. In the presence of calcium ions, intracellular EF-hand modules enhance the catalytic activity of DUOX by stabilizing the dehydrogenase domain in a position that is optimal for electron transfer.
\end{abstract}

\title{
Introduction
}

Reactive oxygen species (ROS) are oxygen-containing chemical species that are highly reactive, such as hydrogen peroxide and superoxide anion ${ }^{1}$. They participate in many physiological processes and are implicated in several pathological conditions ${ }^{1}$. ROS can be generated by a class of dedicated enzymes called NADPH oxidase (NOX) in a highly regulated manner. These enzymes are multi-pass transmembrane proteins that catalyze the reduction of extracellular or luminal oxygen by intracellular NADPH to generate superoxide anion or hydrogen peroxide. NOX proteins are involved in many biological processes including host defense, differentiation, development, cell growth and survival, cytoskeletal reorganization and modification of the extracellular matrix ${ }^{2}$. 
Comprising the human NOX protein family are NOX1-5 and DUOX1-2 ${ }^{2}$. NOX2 protein catalyzes the production of superoxide anion during phagocytosis in neutrophils and is essential for host defense ${ }^{3}$. DUOX 1-2 proteins are highly expressed in thyroid tissue and they catalyze the production of hydrogen peroxide which is important for the biosynthesis of thyroid hormones ${ }^{4}$. The function of DUOX protein requires physical interactions with an auxiliary protein called dual oxidase maturation factor (DUOXA $)^{5}$. DUOXA promotes the maturation and proper plasma membrane localization of DUOX ${ }^{5}$. DUOX protein is encoded by two homologous genes in human namely DUOX1 and DUOX2. Similarly, DUOXA protein is encoded by DUOXA1 and DUOXA2. Loss-of-function mutations of DUOX2 or DUOXA2 in human cause congenital hypothyroidism ${ }^{6}$. Because of the important role of DUOX in thyroid tissue, they are also named thyroid oxidase $(\mathrm{ThOX})^{4}$.

NOX family proteins share a common catalytic core, formed by a haem-coordinating transmembrane domain (TMD) and a cytosolic dehydrogenase (DH) domain ${ }^{7}$. DH domain binds intracellular substrate NADPH and cofactor FAD. In addition to the shared TMD-DH catalytic core of NOX, functional DUOX protein has additional large N-terminal extracellular peroxidase homology domain (PHD), a long intracellular Loop 0 containing two EF-hand domains and it requires an auxiliary DUOXA protein for proper function. The activity of DUOX is regulated by intracellular calcium concentration ${ }^{4}$. Prior to our studies, the structures of NOX family members are only available in the form of isolated domains, including DH domain (PDB ID: $5 \mathrm{O} 0 \mathrm{X})^{8}$ and TMD (PDB ID: 5O0T) ${ }^{8}$ of NOX5 from the algea Cylindrospermum stagnale (csNOX5) and a subdomain of human NOX2 DH domain (PDB ID: 3A1F). Despite the functional importance of DUOX and other NOX family members, their structures in the context of full-length functional protein complex are still unknown. Several open questions for DUOX remain elusive: How is the 
DH domain engaged with TMD to perform the catalytic redox reaction? How does DUOXA protein interact and co-assemble with DUOX? How is the activity of DUOX regulated by intracellular calcium? To answer these fundamental questions, we sought to characterize DUOXDUOXA protein complex both structurally and functionally.

\section{Structure determination}

To express the human DUOX1 (hDUOX1) protein, we constructed the matured hDUOX1 protein (20-1551) in frame with N-terminal GFP tag guided by rat FSH $\beta$ signal peptide for efficient secretion ${ }^{9}$. The molecular weight of GFP-tagged hDUOX1 is $219 \mathrm{kDa}$. To monitor the formation of DUOX1-DUOXA1 complex, we fused the human DUOXA1 (hDUOXA1) protein with a C terminal MBP-mScarlet tag to increase its molecular weight to $106 \mathrm{kDa}$. Fluorescence size exclusion chromatography (FSEC) showed the co-expression of hDUOXA1 effectively shifted the peak of hDUOX1 towards higher molecular weight, suggesting the formation of a stable hDUOX1-hDUOXA1 hetero-complex (Fig.S1a,b). The peak positions indicated hDUOX1 migrated as a monomer, while hDUOX1-hDUOXA1 complex migrated as a hetero-tetramer (Fig.S1b). Moreover, we found the co-expression of DUOX1 and DUOXA1 resulted in cell membranes that showed robust calcium-activated, NADPH-dependent hydrogen peroxide production detected by the Amplex Red assay ${ }^{10}$ (Fig.1a-c). In the low-calcium condition, DUOX1-DUOXA1 complex showed low basal activity (Fig. 1b,c). Addition of calcium not only reduced the $\mathrm{K}_{\mathrm{m}}$ but also increased the $\mathrm{K}_{\mathrm{cat}}$ of DUOX1 complex, leading to the overall enhancement of enzymatic activity (Fig.1b,c).

We solubilized and reconstituted hDUOX1-hDUOXA1 complex into peptidisc using NSPr ${ }^{11}$. Purified peptidisc sample showed a homogenous peak on size exclusion chromatography 
(Fig.S1c) and two major protein bands on SDS-PAGE, both of which could be trimmed upon PNGase F treatment (Fig.S1d), suggesting both of hDUOX1 and hDUOXA1 were modified by N-linked glycosylation. UV-Vis spectrum showed the peptidisc sample has characteristic Soret band with peak at $415 \mathrm{~nm}$ (Fig.S1e), indicating proper Fe(III) haem incorporation. Moreover, the highly purified peptidisc sample recapitulated the calcium-activated NADPH-dependent hydrogen peroxide production observed on membrane (Fig. S1f), confirming that the calciumdependent activation is a built-in mechanism of hDUOX1-hDUOXA1 protein complex. We prepared cryo-EM grids using the peptidisc sample, either in the presence of $2.5 \mathrm{mM}$ EGTA (low-calcium) or $0.5 \mathrm{mM}$ free calcium (high-calcium). Both samples contained $0.1 \mathrm{mM} \mathrm{FAD}$ as cofactor and $0.5 \mathrm{mM}$ NADPH as substrate.

Single particle cryo-EM analysis showed the purified protein was homogeneous and showed two-fold symmetry (Figs.S2-S4). The overall resolution of cryo-EM maps in the low-calcium and high-calcium states reached 2.7 $\AA$ and 2.6 , respectively (Table S1). The extracellular domains and TMD showed better local resolution than the cytosolic domains, suggesting the higher mobility of the cytosolic domains (Figs.S2g and S4g). To further improve the map quality of cytosolic domains, we exploited symmetry expansion ${ }^{12}$ and multibody refinement ${ }^{13}$ by dividing one protomer into the large body (extracellular domain and transmembrane domain) and the small body (the cytosolic domains) (Figs.S2c and S4c). The final resolutions of cytosolic domain reached $3.4 \AA$ and $3.2 \AA$ for the low-calcium and high-calcium states, respectively (Figs.S2-4, Table S1). The high map quality and available homology structures allowed us to build the order regions of the complex which encompassed $88 \%$ of DUOX1 and $79 \%$ of DUOXA1 (Figs.S5-8, Table S1). In the following text, we will focus on the high-calcium state structure unless noted otherwise, because of its higher resolution. 


\section{The architecture of hDUOX1-hDUOXA1 protein complex}

hDUOX1 subunits and hDUOXA1 subunits co-assemble into a 2:2 heterotetrameric protein complex with molecular weight around $457 \mathrm{kDa}$. The complex encompasses $140 \AA \times 105 \AA \times 160$ $\AA$ 3D space and has an overall two-fold rotational symmetry (Fig.1d-f). Vertically, the complex can be divided into three layers: the extracellular layer, the transmembrane layer and the cytosolic layer (Fig.1d). In the extracellular layer, the two large N-terminal PHD domain of hDUOX1 pack against each other diagonally and are buttressed by the extracellular domain of DUOXA1 from beneath (Fig.1d-f). The transmembrane layer is formed by 24 transmembrane helices and harbors the haem binding sites that provide the electron transfer pathway across the membrane (Fig. 1g). At the center of the transmembrane layer, there is a large cavity without discernable protein densities, which is probably filled by lipids on the cell membrane (Fig. 1g). The cytosolic layer is comprised of the catalytic DH domain and regulatory domains for intracellular calcium sensing (Fig.1f,i).

\section{Structure of the catalytic hDUOX1 subunit}

hDUOX1 is the catalytic subunit of the complex (Fig.2). On the extracellular side of hDUOX1 resides the large N-terminal PHD domain which shares sequence homology with several peroxidases, such as peroxidase A from Dictyostelium discoideum (DdPoxA, PDB ID: 6ERC) ${ }^{14}$ (Fig.S9a). Functional peroxidases utilize histidine-coordinated haem as the cofactor for catalysis. However, key residues for haem binding, such as the haem ligand histidine, are missing in the PHD of hDUOX1. Indeed, we did not observe any haem density in the structure of hDUOX1 PHD, suggesting PHD is probably not enzymatic functional in term of peroxidase activity. Close inspection of the map reveals two putative cation densities in PHD. One cation (cation binding 
site 1, CBS1) is coordinated by the side chains of D397 and T332, and the main chain carbonyl groups of V399, T332 and R395 (Fig.S9b). The second cation (CBS2) is coordinated by the side chain of D109, D174, S176 and T170 and the carbonyl groups of T170 and W172 (Fig.S9b). We observed strong densities in these two sites in both low-calcium and high-calcium conditions (Fig.S9b), suggesting the bound cations are probably sodium ions which were present in large quantities in our protein sample or calcium ions that bind very tightly. Both CBS1 and CBS2 are evolutionary conserved in DUOX (Fig. S5) and DdPoxA ${ }^{14}$ (Fig.S9c), indicating their functional importance. Interestingly, we found both CBS1 mutant (D397A+T332A) and CBS2 mutant (D109A+D174A) of DUOX1 failed to co-assemble with DUOXA1 (Fig. S9d). Because CBS1 and CBS2 are away from the subunit interfaces in the DUOX1-DUOXA1 complex, we speculate these mutants probably affect the folding of PHD domain, suggesting the role of CBS1 and CBS2 in protein stability.

The PHD packs on top of the transmembrane domain of DUOX1 through multiple non-covalent interactions (Fig.2a). Moreover, a disulfide bond between C118 on PHD and C1165 on loop C of TMD further staples the bottom of PHD onto the top of TMD (Fig.2a,d). In the TMD, hDUOX1 has an extra bent M0 helix at the periphery of M3 and M4, together with the canonical 6 TM helices of NOX protein family. M1-M6 of hDUOX1 form two haem binding sites within the transmembrane domain. H1144 on M3 and H1238 on M5 coordinate the outer haem (Fig.2b). H1130 on M3 and H1225 on M5 coordinate the inner haem (Fig.2c). These four histidines are absolutely conserved in NOX family proteins (Fig.S6). We observed a spherical density surrounded by the invariant R1087 on M2, H1148 on M3 and outer haem-coordinating residue H1144 (Fig.2b and S3c). Previous studies showed mutations of the csNOX5 residues corresponding to R1087 and H1148 of hDUOX1 affected the re-oxidation of dithionite-reduced 
TMD by oxygen and this site was proposed to be the oxygen substrate binding site, namely oxygen-reducing center (Fig.S10a,b) ${ }^{8}$. Our structure observations in hDUOX1 support the hypothesis.

Preceding the M1 helix of DUOX1 TMD, an amphipathic preM1 helix floats on the inner leaflet of plasma membrane (Fig.1h). This helix was previously observed in $\operatorname{csNOX} 5^{8}$ and is probably a shared feature of NOX family proteins. Between M0 and pre-M1 is a long cytosolic fragment loop 0. Cryo-EM maps reveal that the $\mathrm{N}$ terminal of loop 0 is a domain rich of $\beta$ sheets (Fig.S3g and $\mathrm{S} 10 \mathrm{c})$. Structural search using DALI server ${ }^{15}$ identified the $\beta$ sheets-rich domain is a crypto pleckstrin homology-like domain (PHLD) that shares little sequence homology but high structural similarity to the pleckstrin homolog (PH) domain proteins (Fig.S10c) $)^{16}$.

Following the PHLD, two EF-hand type calcium binding domains (EF1 and EF2) form a compact helical module that is connected to the PHLD through $\alpha \mathrm{C}$ (Fig.S6). Residues predicted to be responsible for calcium binding in EF1 and EF2 are evolutionary conserved in DUOX family proteins (Fig.S6). Although we did not observe the strong densities for small calcium ions due to poor local resolution (Figs.S2-3), the structure of EF-hand module closely resembles the small subunit of calcium-dependent protein phosphatase calcineurin in calcium-bound state (PDB ID: 4IL1) ${ }^{17}$ (Fig.S10d), suggesting both EF1 and EF2 are loaded with calcium in the highcalcium state. Based on the homology structure (4IL1), side chains of D828, D830, N832 and E839 and the main chain carbonyl group of Y834 chelate one calcium ion in EF1 (Fig.S10e) and side chains of D864, D866, N868, E875 and the main chain carbonyl group of L870 chelate another calcium ion in EF2 (Fig.S10f). It is reported that mutations of any of these calcium binding sites abolished calcium activation ${ }^{18}$ and E879K mutation in hDUOX2 (E875 in 
hDUOX1) lead to congenital hypothyroidism ${ }^{19}$, emphasizing their importance in calcium activation.

The C-terminal catalytic DH domain is connected to M6 of DUOX1 TMD via a short linker (Fig.1h,i). DH domain of hDUOX1 has a canonical dehydrogenase fold and its structure is similar to $\operatorname{csNOX} 5^{8}$ (Figs.1i and S7). We observed strong densities for both FAD cofactor and NADPH substrate and their binding sites were contributed from not only DH domain but also TMD (Fig.2h,i), as described later.

\section{Inter-domain interactions in the high-calcium state stabilize the electron transfer pathway}

In the high-calcium state, individual domains of DUOX1 in the cytosolic layer are stabilized by multiple inter-domain interactions. The PHLD interacts with adjacent TMD and DH domains (Fig.2e). The main chain carbonyl group of K653 on PHLD makes hydrogen bond with R1215 on loop D of TMD (Fig.2e). Side chain of R674 of PHLD interacts with the main chain carbonyl group of E1348 and I1349 on $\alpha 1$ of DH domain (Fig.2f). The EF1-EF2 module in the highcalcium state shapes a crevice that embraces $\alpha 4$ and post $\alpha 4$ loop of DH domain (Fig.2g and Fig.S10g). The interactions between EF module and DH are mainly hydrophobic and involve F768, F772, F807, F819, F840 and F847 of EF module, L1463, M1467, I1470, F1475, V1478 and F1484 of DH domain (Fig.2g). In addition, K814 of EF module makes electrostatic interaction with E1281 on $\beta 2$ of DH (Fig.2g). The interactions between EF module and DH domain of hDUOX1 mimic the interactions between calcineurin subunit B and A in the calciumbound state (PDB ID: 4IL1) ${ }^{17}$ (Fig.S10g,h).

The linker between EF module and preM1 helices binds in a groove on the surface of DH domain (Fig.1i). DH docks onto the bottom of TMD via polar interaction between R1270 on M6 
and D1367 on $\beta 7$, and between R1113 on loop B of TMD and N1550 of DH (Fig.2h,i). It is reported that R1111Q mutation in hDUOX2 (R1113 in hDUOX1) was identified in congenital hypothyroidism patients ${ }^{19}$, highlighting the importance of this inter-domain interaction.

Moreover, both the FAD cofactor and NADPH substrate bind at the interface between DH and TMD. R1214 and R1131 in TMD form electrostatic interaction with phosphate of FAD. D1128 makes hydrogen bonding with ribose of FAD (Fig.2h). E1039 and N1040 in TMD make hydrogen bonding with adenosine ring of NADPH, and R1036 make cation- $\pi$ interaction with both adenosine ring and electrostatic interaction with phosphate group of NADPH (Fig.2i). Notably, R1495, R1424 and R1036 all participate in electrostatic interactions with the phosphate group of NADPH ribose, providing structural mechanism to distinguish NADPH from NADH (Fig.2i). Through structural comparison, we found the NADPH binding site in csNOX5 structure was blocked by the artificially engineered C-terminal insertion which was introduced into previous crystallization construct ${ }^{8}$ (Fig.S10i). Moreover, the adenosine group of FAD has a $180^{\circ}$ flip compared with structure of isolated DH of csNOX5 (Fig.S10j), suggesting the TMD has strong influence on the binding and conformation of the FAD molecule. Taken together, the binding of FAD and NADPH onto hDUOX1 would bridge and stabilize the docking of DH onto TMD.

The aforementioned inter-domain interactions involve a complex nexus among PHLD, EF-hand module, DH domain and TMD, and stabilize DUOX1 in a catalytic competent conformation for efficient electron transfer. In this conformation, the measured edge-to-edge distances between NADPH and FAD, between FAD and inner haem, and between inner haem and outer haem are $8.2 \AA, 3.9 \AA$ and $6.7 \AA$, respectively (Fig.3a). It is possible that there are additional protein residues on DUOX1 that also participate in the electron rely process. At the end of electron 
transfer chain, the initial product of oxygen reducing reaction is superoxide anion. We probed the possible pathways for oxygen entrance and for superoxide anion exit with CAVER ${ }^{20}$, using oxygen-reducing center as the starting point. We located four possible tunnels: tunnel A is formed by M1, M2, M5 and M6 and is capped by loop E on top (Fig.3b); tunnel B is surrounded by M2, loop A, loop C and loop E (Fig.3c); tunnel C is embraced by M3, M4 and loop C (Fig.3d); tunnel D is enclosed by M3, M4, loop C and M0 (Fig.3e). The bottleneck radii of these tunnels are around $1 \AA ̊$ (Fig.3f), which may allow the permeation of small oxygen substrate under dynamic motion of DUOX1 protein. Further analysis showed tunnel B-D are all surrounded by hydrophobic residues (Fig.3c-e), which are unfavorable for superoxide anion permeation. In contrast, tunnel A is gated by hydrophilic R1087 on M2, R1062 on M1, R1248 and Q1245 on loop E (Fig.3b). We speculate the highly positively charged constriction of tunnel A would strongly attract the negatively charged superoxide anions, and this might be essential for the dismutation reaction between two superoxide anions to generate uncharged hydrogen peroxide for diffusion. Therefore, manipulations that may alter the constrictions of tunnel A-D would affect superoxide anion intermediate leakage. Indeed, it is reported that mutations on DUOX1 loop A or on DUOXA1 NTP which interacts with and stabilizes loop A would change the ratio of superoxide anion and hydrogen peroxide produced, probably by affecting the leakage of superoxide anions through these tunnels ${ }^{21-23}$.

\section{Structure of hDUOXA1 and mechanism of complex assembly}

DUOXA protein is an essential auxiliary subunit for DUOX enzyme ${ }^{5}$ (Fig.S11a) and it has an extracellular N-terminus that is important for hydrogen peroxide generation ${ }^{22,23}$. We observed the N-terminus peptide (NTP) of hDUOXA1 extends and packs onto the PHD-TMD junction of the distal hDUOX1 subunit (Fig.4a-g). Side chains of F8, F10 and Y11 of NTP insert into the 
hydrophobic groove formed by loop C, loop A and PHD of hDUOX1 (Fig.4c). In addition, K15 of DUOXA1 NTP makes electrostatic interactions with D1077 of DUOX1 (Fig.4d). This agrees with previous data showing DUOXA1 NTP interacts with DUOX1 loop $\mathrm{A}^{21}$. hDUOXA1 has five transmembrane helices. Lower part of TM1 interacts with preM1 and M1 of hDUOX1 (Fig.S11a). The remaining four helices and associated extracellular loops share structural similarity with claudin superfamily members, such as claudin-9 (PDB ID:6OV2) ${ }^{24}$ (Fig.S11). The extracellular loop between TM2 and TM3 folds into a compact claudin-like domain (CLD) composed of four $\beta$ strands and two $\alpha$ helices (Fig.S8 and S11). CLD forms extensive interactions with both distal and proximal DUOX1 subunits (Fig.4a,b), emphasizing its important role in the complex assembly. This agrees with previous studies showing that splicing variants at TM2-TM3 loop have distinct behavior in supporting the activity of DUOX $1^{22}$. Moreover, we found an ordered N-linked glycosylation decoration on N109 of hDUOXA1 and its branched sugar moieties make extensive polar interactions with both DUOXA1 and DUOX1 subunits (Fig.4a,b). The PHD of two DUOX1 subunits also interact with each other (Fig.4a,b). Close to the dyad axis, R50 and R507 on one PHD make polar interactions with E41 and F313 on the opposite PHD (Fig.4e). We further analyzed the effects of interface mutations on the tetramer assembly and found mutations of R50E, R507E and R507A all severally affect tetrameric peak formation on FSEC (Fig.4f). These structural information and biochemical data revealed the detailed inter-subunit interactions that dictate the hetero-tetramer assembly.

\section{Activation mechanism of DUOX1 complex by calcium}

The consensus map in the low-calcium state showed the cytosolic layer had poor local resolution which was improved by multibody refinement ${ }^{13}$ (Fig.S4). Further molecular flexibility analysis

13 showed the cytosolic domains (small body) in the low-calcium state were sampling a broad 
range of orientations relative to the transmembrane domain, evidenced by the plateau-shaped distribution on the histogram of the major eigenvector (Fig. S4f). This is in great contrast to the normal distribution in the high-calcium state (Fig. S2f), suggesting the cytosolic layer in the lowcalcium state is more flexible. We compared the structures in the low-calcium state and highcalcium state and found structural changes in the extracellular layer and transmembrane layer are small (Fig.5a). However, there are large conformational changes of the regulatory PHLD and EF-hand module in the cytosolic layer (Fig.5a-c, Movie S1). In the absence of calcium, the EF module switches from an extended shape into a more contracted shape (Fig.5d-e), which reconfigures the interface between EF module and $\alpha 4$ of DH domain, resulting in a loosely packed structure (Fig.5f). In the low-calcium state, EF2 moves away from DH domain. The C $\alpha$ atom of A894 on $\alpha \mathrm{J}$ of EF2 has $40 \AA$ displacement (Fig. 5b). PHLD rotates away from the TMD and DH domain and $\alpha \mathrm{A}$ of PHLD has $17.2^{\circ}$ outward rotation (Fig.5c). As a result, several interdomain interactions observed in the high-calcium state were disrupted and therefore the docking of DH domain onto TMD is weakened by these structural changes, leading to a higher mobility of DH domain (Fig.S4g). We propose the increased mobility of DH domain negatively correlates with the electron transfer efficiency and thus the catalytic activity of DUOX. In addition, because TMD also contributes to FAD and NADPH binding, the increased mobility of DH domain would result in reduced affinity of NADPH as well. This is in agreement with the markedly reduced $\mathrm{K}_{\mathrm{cat}}$ and moderately increased $\mathrm{K}_{\mathrm{m}}$ in the low-calcium state as we observed (Fig.1c).

\section{Conclusions}

In this study, we provided the structures of hDUOX1-hDUOXA1 as a hetero-tetrameric protein complex in both high-calcium state and low-calcium state. The structure of hDUOX1 complex in the high-calcium state reveals multiple inter-domain interactions that optimally orientate DH 
domain and TMD for efficient electron transfer and thus redox reaction. Removal of calcium ions results in the reconfiguration of cytosolic inter-domain interactions which in turn mobilizes the DH domain, and lowers the electron transfer efficiency (Fig.6). These structures provide mechanistic insights into the structure and mechanism of DUOX and other NOX enzymes.

\section{Materials and Methods}

\section{Cell culture}

HEK293F suspension cells (Thermo Fisher Scientific) were cultured in Freestyle 293 medium (Thermo Fisher Scientific) supplemented with $1 \% \mathrm{FBS}$ at $37^{\circ} \mathrm{C}$ with $6 \% \mathrm{CO}_{2}$ and $70 \%$ humidity. Sf9 insect cells (Thermo Fisher Scientific) were cultured in SIM SF (Sino Biological) at $27^{\circ} \mathrm{C}$. The cell lines were routinely checked to be negative for mycoplasma contamination.

\section{Protein expression and purification}

We constructed a modified BacMam vector ${ }^{25,26}$ with N-terminal GFP tag guided by rat FSH $\beta$ signal peptide ${ }^{9}$ and cloned human DUOX1 into this vector. The cDNAs of human DUOXA1 were cloned into a non-tagged BacMam vector ${ }^{25,26}$. The two expression were further merged into one bicistronic vector by the LINK sequence on the modified vector ${ }^{25,27}$. The baculoviruses were produced using the Bac-to-Bac system and amplified in Sf9 cells. For protein expression, HEK293F cells cultured in Freestyle 293 medium at density of $2.8 \times 10^{6} \mathrm{ml}^{-1}$ were infected with $15 \%$ volume of $\mathrm{P} 2$ virus. $10 \mathrm{mM}$ sodium butyrate was added to the culture 12 hours post infection and transferred to a $30^{\circ} \mathrm{C}$ incubator for another 36 hours before harvesting. Cells were collected by centrifugation at 4,000 rpm (JLA 8.1000, Beckman) for 10 min, and washed with 20 $\mathrm{mM}$ Tris ( $\mathrm{pH} 8.0$ at $\left.4^{\circ} \mathrm{C}\right), 150 \mathrm{mM} \mathrm{NaCl}, 2 \mathrm{mM}$ ethylene glycol tetraacetic acid (EGTA), $2 \mu \mathrm{g} / \mathrm{ml}$ aprotinin, $2 \mu \mathrm{g} / \mathrm{ml}$ pepstatin, $2 \mu \mathrm{g} / \mathrm{ml}$ leupeptin, flash frozen and storage at $-80^{\circ} \mathrm{C}$. 
For each batch of protein purification, cell pellet corresponding to 0.5 liter culture was thawed and extracted with $20 \mathrm{ml}$ Buffer A $\left[20 \mathrm{mM}\right.$ Tris $\mathrm{pH} 8.0$ at $4{ }^{\circ} \mathrm{C}, 150 \mathrm{mM} \mathrm{NaCl}, 5 \mu \mathrm{g} / \mathrm{ml}$ aprotinin, $5 \mu \mathrm{g} / \mathrm{ml}$ pepstatin, $5 \mu \mathrm{g} / \mathrm{ml}$ leupeptin, 20\% (v/v) glycerol, 2 mM EGTA] containing $1 \mathrm{mM}$ phenylmethanesulfonyl fluoride (PMSF) and 1\% (w/v) digitonin (Biosynth) at $4^{\circ} \mathrm{C}$ for 50 min. 1 mM iodoacetamide (Sigma - I1 149) was added during the detergent extraction procedure to reduce non-specific cysteine crosslinking. The supernatant was ultra-centrifuged at 50,000 rpm (TLA100.3, Beckman) for $50 \mathrm{~min}$. The solubilized proteins were loaded onto $5 \mathrm{ml}$ Streptactin Beads 4FF (Smart-Lifesciences) column and washed with $20 \mathrm{ml}$ Buffer A+ $0.1 \%$ digitonin. The column was washed with $100 \mathrm{ml}$ Buffer $\mathrm{A}+0.1 \%$ digitonin plus $10 \mathrm{mM} \mathrm{MgCl}_{2}$ and $1 \mathrm{mM}$ adenosine triphosphate (ATP) to remove contamination of heat shock proteins. Then the column was washed with $40 \mathrm{ml}$ Buffer $\mathrm{A}+0.1 \%$ digitonin again to remove residual $\mathrm{MgCl}_{2}$ and ATP. The target protein was assembled into the peptidisc on the Streptactin Beads through applying 4 $\mathrm{ml} 1 \mathrm{mg} / \mathrm{ml}$ NSPr in $20 \mathrm{mM}$ Tris pH $8.0^{11}$. Then the column was washed with $100 \mathrm{ml}$ Buffer A to remove free NSPr. The assembled peptidiscs were eluted with $40 \mathrm{ml}$ Buffer A + $5 \mathrm{mM}$ Ddesthiobiotin (IBA). Eluted protein was concentrated using 100-kDa cut off concentrator (Millipore) and further purified by Superose 6 increase (GE Healthcare) running in HBS (20 mM Hepes pH 7.5, $150 \mathrm{mM} \mathrm{NaCl})+0.5 \mathrm{mM}$ EGTA. Fraction 19 corresponding to DUOX1 + DUOXA1 peptidisc complex was concentrated to A280/415 $=4.4 / 1.4$ with estimated concentration of $10.7 \mu \mathrm{M}$ DUOX1 subunits $\left(\varepsilon_{415}=0.131 \mu \mathrm{M}^{-1} \mathrm{~cm}^{-1}\right)$.

\section{Enzymatic assay}

The membrane fractions of DUOX1 for enzymatic assay were prepared as previously reported with minor modification ${ }^{28}$. Briefly, cells were washed with Buffer A. After centrifuging at 4,000 $\mathrm{rpm}$ for $10 \mathrm{~min}$ at $4^{\circ} \mathrm{C}$, the cell pellets were broken using a needle for 12 times in $1 \mathrm{ml}$ of 20 
$\mathrm{mM}$ Tris $\mathrm{pH} 8.0$ at $4{ }^{\circ} \mathrm{C}$ containing $0.1 \mathrm{mM}$ dithiothreitol, $10 \mathrm{mM}$ EGTA $(\mathrm{pH} 8.0)$ and the mixture of protease inhibitors. The pellet was removed by centrifuging at 7,000 rpm for $15 \mathrm{~min}$, and the supernatant was collected and then centrifuged at 65,000 rpm (TLA100.3, Beckman) for 1 hour. The membrane pellet was resuspended in HBS containning $1 \mathrm{mM}$ EGTA. Meanwhile, 10 $\mu \mathrm{l}$ membrane was solubilized by $100 \mu \mathrm{TBS}+1 \%$ digitonin with the mixture of protease inhibitors for $1 \mathrm{~h}$ at $4{ }^{\circ} \mathrm{C}$ for FSEC. The protein concentrations in the membrane were estimated by comparing their GFP fluorescence signal to that of a purified GFP-tagged DUOX1 complex.

The $\mathrm{H}_{2} \mathrm{O}_{2}$-generating activity of DUOX1 complex was determined using the amplex red assay ${ }^{29}$. The concentrations of $\mathrm{H}_{2} \mathrm{O}_{2}$ solution were determined by measuring UV-Vis absorbance at 240 $\mathrm{nm}$ with spectrophotometer (Pultton) and calculated using molar extinction coefficient of 43.6 $\mathrm{M}^{-1} \mathrm{~cm}^{-1}$. The concentration of $\mathrm{H}_{2} \mathrm{O}_{2}$ solution was further validated by reacting with Amplex red to generate resorufin which has $\varepsilon_{571}=69,000 \mathrm{M}^{-1} \mathrm{~cm}^{-1} 29$. Then the $\mathrm{H}_{2} \mathrm{O}_{2}$ solution with known concentration was used to calibrate the resorufin fluorescence curve (excitation, $530 \mathrm{~nm}$; emission, $590 \mathrm{~nm}$ ) measured using a Microplate Reader (BioTek Synergy HT) at $37{ }^{\circ} \mathrm{C}$.

The $\mathrm{H}_{2} \mathrm{O}_{2}$-generating reaction of the membrane fraction containing DUOX1 complex was performed at $37{ }^{\circ} \mathrm{C}$ in $0.15 \mathrm{ml}$ of $\mathrm{HBS}$ with $1 \mathrm{mM}$ EGTA, $10 \mu \mathrm{M}$ FAD, $100 \mu \mathrm{M}$ NADPH, $50 \mu \mathrm{M}$ amplex red, $0.067 \mathrm{mg} / \mathrm{ml}$ horseradish peroxidase and $0.0576 \mathrm{mg} / \mathrm{ml} \mathrm{SOD} . \mathrm{Ca}^{2+}$ concentrations were determined using fluorescent indicators fura-2 or fluo3-FF. The $\mathrm{K}_{\text {cat }}$ and $\mathrm{K}_{\mathrm{m}}$ values of the membrane fraction containing DUOX1 complex were determined at $37^{\circ} \mathrm{C}$ with different concentrations of NADPH in the presence or absence of $1.4 \mathrm{mM} \mathrm{CaCl}_{2}$. The $\mathrm{H}_{2} \mathrm{O}_{2}$-generating reaction of the purified DUOX1 complex in peptidisc was performed at $27^{\circ} \mathrm{C}$ in $0.15 \mathrm{ml}$ of $\mathrm{HBS}$ $+1 \mathrm{mM}$ EGTA, $10 \mu \mathrm{M}$ FAD, $100 \mu \mathrm{M}$ NADPH, $50 \mu \mathrm{M}$ amplex red, $0.067 \mathrm{mg} / \mathrm{ml}$ horseradish peroxidase and $0.0576 \mathrm{mg} / \mathrm{ml} \mathrm{SOD}$ in the presence or absence of $1.1 \mathrm{mM} \mathrm{CaCl}_{2}$. Progress of the 
reactions was monitored continuously by following the increase of the resorufin fluorescence, and the initial rates were calculated from the linear slopes of the progress curves. The activity of DUOX1 complex was determined by minusing the background of the corresponding buffer without DUOX1 samples.

\section{Cryo-EM sample preparation and data acquisition}

The peptidisc sample was supplemented with $2.5 \mathrm{mM}$ EGTA (low-calcium) or $0.5 \mathrm{mM}$ free calcium (high-calcium) for cryo-EM analysis, respectively. Both samples contain $100 \mu \mathrm{M}$ FAD as the cofactor and $500 \mu \mathrm{M}$ NADPH as the substrate. To overcome the preferred orientation problem, $0.5 \mathrm{mM}$ non-solubilizing detergent fluorinated octyl-maltoside was added to the sample before cyro-EM sample preparation. Aliquots of $1.5 \mu \mathrm{L}$ protein sample were placed on graphene oxide $(\mathrm{GO})$ coated grids as previously reported ${ }^{30}$. Grids were blotted for $3 \mathrm{~s}$ at $100 \%$ humidity and flash-frozen in liquid ethane cooled by liquid nitrogen using Vitrobot Mark I (FEI). Grids were then transferred to a Titan Krios (FEI) electron microscope that was equipped with a Gatan GIF Quantum energy filter and operated at $300 \mathrm{kV}$ accelerating voltage. Image stacks were recorded on a Gatan K2 Summit direct detector in super-resolution counting mode using SerialEM at a nominal magnification of $130,000 \times($ calibrated pixel size of $1.045 \AA$ A pixel), with a defocus ranging from -1.5 to $-2.0 \mu \mathrm{m}$. Each stack of 32 frames was exposed for $7.12 \mathrm{~s}$, with a total dose about $50 \mathrm{e}^{-/} \AA^{2}$ and a dose rate of $8 \mathrm{e}^{-} / \mathrm{pixel} / \mathrm{s}$ on detector.

\section{Image processing}

The image processing workflow is illustrated in Fig. S2 and Fig. S4. A total of 7,076 superresolution movie stacks of the high-calcium state sample and 2,076 stacks of the low-calcium state sample were collected using Serial EM, and motion-corrected, dose weighted and two-fold 
binned to a pixel size of $1.045 \AA$ using MotionCor $2{ }^{31}$. Contrast transfer function (CTF) parameters were estimated with $\operatorname{Gctf}^{32}$. Micrographs with ice or ethane contamination, and empty carbon were removed manually. Autopicking were performed using Gautomatch (kindly provided by Kai Zhang). All subsequent classification and reconstruction was performed in Relion $3.1^{33}$ unless otherwise stated. Reference-free 2D classification was performed to remove contaminants. Initial model was generated using cryoSPARC ${ }^{34}$. Particles were subjected to multi-reference 3D classification ${ }^{35,36}$ and random-phase $3 \mathrm{D}$ classification ${ }^{35,36}$. Phaserandomized models were generated from the model obtained from previous refinement using randomize software (from the lab of Nikolaus Grigorieff). Further CTF refinement was then performed with Relion 3.1 using C2 symmetry. The particles were then re-extracted, re-centered, and re-boxed from 256 pixels to 320 pixels for consensus refinement. To improve the density of cytosolic layer, particles were symmetry expended ${ }^{12}$ for multibody refinement ${ }^{13}$. One soft mask (the large body) that covers the extracellular domain together with transmembrane domain of one protomer was generated from the consensus map using UCSF Chimera and Relion $3.1^{37}$. The other soft mask (the small body) covers the cytosolic domains of the same protomer. 3D multibody refinements ${ }^{13}$ were performed using the two soft masks and the parameters determined from previous consensus refinement. The motions of the bodies were analyzed by relion_flex_analyse in Relion $3.1^{37}$. The two half-maps of each body generated by 3D multibody refinement were subjected to post-processing in Relion $3.1^{37}$. The masked and sharpened maps of each body were aligned to the consensus map using UCSF Chimera ${ }^{37}$ and summed using Relion $3.1^{37}$ to generate the composite maps for visualization and model building. All of the resolution estimations were based on a Fourier shell correlation (FSC) of 0.143 cutoff after correction of the masking effect. B-factor used for map sharpening was automatically determined 
by the post-processing procedure in Relion $3.1^{33}$. The local resolution was estimated with Relion $3.1^{33}$.

\section{Model building}

The composite maps derived from multibody refinement were used for model building. The structures of PHD, TMD, EF1-2 and DH domains of hDUOX1 were generated using phyre2 server ${ }^{38}$ based on PDB ID: 6ERC, 5O0T, 4IL1 and 5O0X, and manually docked into the cryoEM maps using Chimera ${ }^{37}$. Initial models of PHLD were generated by Rosetta Web Server using ab initio mode ${ }^{39}$, manually selected according to the distances calculated by RaptorX Contact Prediction server ${ }^{40}$ and validated by the fitting between model and cryo-EM densities, especially the location of bulky aromatic residues. The partial model of hDUOXA1 were generated using EM builder ${ }^{41}$. The initial models were iteratively built using $\operatorname{Coot}^{42}$ and refined using Phenix in real space ${ }^{43}$.

\section{Data availability}

Data supporting the findings of this manuscript are available from the corresponding author upon reasonable request. The cryo-EM map of DUOX1-DUOXA1 in the high-calcium and lowcalcium states have been deposited in the EMDB under ID code EMD-30556 and EMD-30555. The atomic coordinate of DUOX1-DUOXA1 in the high-calcium and low-calcium states have been deposited in the PDB under ID code 7D3F and 7D3E, respectively.

\section{Acknowledgement}

We thank Yunlu Kang, Wenjun Guo, Yange Niu, Dian Ding, Mengmeng Wang, Miao Wei and Xiao He for illustration. We thank Miao Wei for making the rat FSH $\beta$ secretion signal-guided 
GFP vector. We thank Prof. Jiahuai Han for providing the cDNA of hDUOX1 and hDUOXA1, Prof. Helmut Grasberger for providing the cDNA of hDUOX2 and hDUOXA2, Prof. Yuji Kohara for providing the cDNA of c.elegans duox-2, bli-3 and doxA1. Cryo-EM data collection was supported by Electron microscopy laboratory and Cryo-EM platform of Peking University with the assistance of Xuemei Li, Daqi Yu, Xia Pei, Bo Shao, Guopeng Wang, and Zhenxi Guo. Part of structural computation was also performed on the Computing Platform of the Center for Life Science and High-performance Computing Platform of Peking University. This work is supported by grants from the Ministry of Science and Technology of China (National Key R\&D Program of China, 2016YFA0502004 to L.C.), National Natural Science Foundation of China (91957201, 31622021, 31870833 and 31821091 to L.C., 31900859 to J.-X. W.), Beijing Natural Science Foundation (5192009 to L.C.), and Young Thousand Talents Program of China to L.C., and the China Postdoctoral Science Foundation (2016M600856, 2017T100014, 2019M650324, and 2019T120014 to J.-X.W.). J.-X. W. is supported by the Boya Postdoctoral Fellowship of Peking University and the postdoctoral foundation of the Peking-Tsinghua Center for Life Sciences, Peking University (CLS).

\section{Author contributions}

Lei Chen initiated the project. Jing-Xiang Wu purified proteins and prepared the cryo-EM samples, collected the cryo-EM data and processed the cryo-EM data. Lei Chen built and refined the atomic model. Rui Liu and Kangcheng Song screened NOX constructs. All authors contributed to the manuscript preparation.

\section{Conflict of Interest}

The authors declare no conflict of interests. 
1 Sies, H. \& Jones, D. P. Reactive oxygen species (ROS) as pleiotropic physiological signalling agents. Nat. Rev. Mol. Cell Biol., doi:10.1038/s41580-020-0230-3 (2020).

2 Lambeth, J. D. \& Neish, A. S. Nox enzymes and new thinking on reactive oxygen: a double-edged sword revisited. Annu. Rev. Pathol. 9, 119-145, doi:10.1146/annurevpathol-012513-104651 (2014).

3 Winterbourn, C. C., Kettle, A. J. \& Hampton, M. B. Reactive Oxygen Species and Neutrophil Function. Annu. Rev. Biochem. 85, 765-792, doi:10.1146/annurev-biochem060815-014442 (2016).

4 Ohye, H. \& Sugawara, M. Dual oxidase, hydrogen peroxide and thyroid diseases. Exp Biol Med (Maywood) 235, 424-433, doi:10.1258/ebm.2009.009241 (2010).

5 Grasberger, H. \& Refetoff, S. Identification of the maturation factor for dual oxidase. Evolution of an eukaryotic operon equivalent. J. Biol. Chem. 281, 18269-18272, doi:10.1074/jbc.C600095200 (2006).

6 Weber, G., Rabbiosi, S., Zamproni, I. \& Fugazzola, L. Genetic defects of hydrogen peroxide generation in the thyroid gland. J. Endocrinol. Invest. 36, 261-266, doi:10.3275/8847 (2013).

7 Sumimoto, H. Structure, regulation and evolution of Nox-family NADPH oxidases that produce reactive oxygen species. FEBS J. 275, 3249-3277, doi:10.1111/j.17424658.2008.06488.x (2008).

8 Magnani, F. et al. Crystal structures and atomic model of NADPH oxidase. Proc. Natl. Acad. Sci. U. S. A. 114, 6764-6769, doi:10.1073/pnas.1702293114 (2017).

9 Long, D. et al. New insight into the mechanism underlying fibroin secretion in silkworm, Bombyx mori. FEBS J. 282, 89-101, doi:10.1111/febs.13105 (2015).

10 Forteza, R., Salathe, M., Miot, F. \& Conner, G. E. Regulated hydrogen peroxide production by Duox in human airway epithelial cells. Am. J. Respir. Cell Mol. Biol. 32, 462-469, doi:10.1165/rcmb.2004-0302OC (2005).

11 Carlson, M. L. et al. The Peptidisc, a simple method for stabilizing membrane proteins in detergent-free solution. Elife 7, doi:10.7554/eLife.34085 (2018).

12 Zhou, M. et al. Atomic structure of the apoptosome: mechanism of cytochrome c- and dATP-mediated activation of Apaf-1. Genes Dev. 29, 2349-2361, doi:10.1101/gad.272278.115 (2015).

13 Nakane, T., Kimanius, D., Lindahl, E. \& Scheres, S. H. Characterisation of molecular motions in cryo-EM single-particle data by multi-body refinement in RELION. eLife 7, doi:10.7554/eLife.36861 (2018).

14 Nicolussi, A. et al. Secreted heme peroxidase from Dictyostelium discoideum: Insights into catalysis, structure, and biological role. J. Biol. Chem. 293, 1330-1345, doi:10.1074/jbc.RA117.000463 (2018).

15 Holm, L. Benchmarking fold detection by DaliLite v.5. Bioinformatics 35, 5326-5327, doi:10.1093/bioinformatics/btz536 (2019). 
16 Feng, J., He, L., Li, Y., Xiao, F. \& Hu, G. Modeling of PH Domains and Phosphoinositides Interactions and Beyond. Adv. Exp. Med. Biol. 1111, 19-32, doi:10.1007/5584_2018_236(2019).

17 Ye, Q. et al. Structural basis of calcineurin activation by calmodulin. Cellular signalling 25, 2661-2667, doi:10.1016/j.cellsig.2013.08.033 (2013).

18 Rigutto, S. et al. Activation of dual oxidases Duox1 and Duox2: differential regulation mediated by camp-dependent protein kinase and protein kinase C-dependent phosphorylation. J. Biol. Chem. 284, 6725-6734, doi:10.1074/jbc.M806893200 (2009). Peters, C. et al. DUOX2/DUOXA2 Mutations Frequently Cause Congenital Hypothyroidism that Evades Detection on Newborn Screening in the United Kingdom. Thyroid 29, 790-801, doi:10.1089/thy.2018.0587 (2019).

20 Chovancova, E. et al. CAVER 3.0: a tool for the analysis of transport pathways in dynamic protein structures. PLoS Comput. Biol. 8, e1002708, doi:10.1371/journal.pcbi.1002708 (2012).

21 Ueyama, T. et al. The extracellular A-loop of dual oxidases affects the specificity of reactive oxygen species release. J. Biol. Chem. 290, 6495-6506, doi:10.1074/jbc.M114.592717 (2015).

22 Morand, S. et al. Duox maturation factors form cell surface complexes with Duox affecting the specificity of reactive oxygen species generation. FASEB J. 23, 1205-1218, doi:10.1096/fj.08-120006 (2009).

23 Hoste, C., Dumont, J. E., Miot, F. \& De Deken, X. The type of DUOX-dependent ROS production is dictated by defined sequences in DUOXA. Exp. Cell Res. 318, 2353-2364, doi:10.1016/j.yexcr.2012.07.007 (2012).

24 Vecchio, A. J. \& Stroud, R. M. Claudin-9 structures reveal mechanism for toxin-induced gut barrier breakdown. Proc. Natl. Acad. Sci. U. S. A. 116, 17817-17824, doi:10.1073/pnas.1908929116 (2019).

25 Li, N. et al. Structure of a Pancreatic ATP-Sensitive Potassium Channel. Cell 168, 101110 e110, doi:10.1016/j.cell.2016.12.028 (2017).

26 Goehring, A. et al. Screening and large-scale expression of membrane proteins in mammalian cells for structural studies. Nat. Protoc. 9, 2574-2585, doi:10.1038/nprot.2014.173 (2014).

27 Scheich, C., Kummel, D., Soumailakakis, D., Heinemann, U. \& Bussow, K. Vectors for co-expression of an unrestricted number of proteins. Nucleic Acids Res. 35, e43, doi:10.1093/nar/gkm067 (2007).

28 Ameziane-El-Hassani, R. et al. Dual oxidase-2 has an intrinsic Ca2+-dependent H2O2generating activity. The Journal of biological chemistry 280, 30046-30054, doi:10.1074/jbc.M500516200 (2005).

29 Zhou, M., Diwu, Z., Panchuk-Voloshina, N. \& Haugland, R. P. A stable nonfluorescent derivative of resorufin for the fluorometric determination of trace hydrogen peroxide: applications in detecting the activity of phagocyte NADPH oxidase and other oxidases. Anal Biochem 253, 162-168, doi:10.1006/abio.1997.2391 (1997).

30 Phulera, S. et al. Cryo-EM structure of the benzodiazepine-sensitive alpha1beta1gamma2S tri-heteromeric GABAA receptor in complex with GABA. eLife 7, doi:10.7554/eLife.39383 (2018). 
31 Zheng, S. Q. et al. MotionCor2: anisotropic correction of beam-induced motion for improved cryo-electron microscopy. Nat. Methods 14, 331-332, doi:10.1038/nmeth.4193 (2017).

32 Zhang, K. Gctf: Real-time CTF determination and correction. J. Struct. Biol. 193, 1-12, doi:10.1016/j.jsb.2015.11.003 (2016).

33 Zivanov, J. et al. New tools for automated high-resolution cryo-EM structure determination in RELION-3. Elife 7, doi:10.7554/eLife.42166 (2018).

34 Punjani, A., Rubinstein, J. L., Fleet, D. J. \& Brubaker, M. A. cryoSPARC: algorithms for rapid unsupervised cryo-EM structure determination. Nat. Methods 14, 290-296, doi:10.1038/nmeth.4169 (2017).

35 Kang, Y., Wu, J.-X. \& Chen, L. Structure of voltage-modulated sodium-selective NALCN-FAM155A channel complex. bioRxiv, 2020.2007.2026.221747, doi:10.1101/2020.07.26.221747 (2020).

36 Gong, X. et al. Structural Insights into the Niemann-Pick C1 (NPC1)-Mediated Cholesterol Transfer and Ebola Infection. Cell 165, 1467-1478, doi:10.1016/j.cell.2016.05.022 (2016).

37 Pettersen, E. F. et al. UCSF Chimera--a visualization system for exploratory research and analysis. J Comput Chem 25, 1605-1612, doi:10.1002/jcc.20084 (2004).

38 Kelley, L. A., Mezulis, S., Yates, C. M., Wass, M. N. \& Sternberg, M. J. The Phyre2 web portal for protein modeling, prediction and analysis. Nature protocols 10, 845-858, doi:10.1038/nprot.2015.053 (2015).

39 Raman, S. et al. Structure prediction for CASP8 with all-atom refinement using Rosetta. Proteins 77 Suppl 9, 89-99, doi:10.1002/prot.22540 (2009).

40 Wang, S., Sun, S., Li, Z., Zhang, R. \& Xu, J. Accurate De Novo Prediction of Protein Contact Map by Ultra-Deep Learning Model. PLoS Comput. Biol. 13, e1005324, doi:10.1371/journal.pcbi.1005324 (2017).

41 Zhou, N., Wang, H. \& Wang, J. EMBuilder: A Template Matching-based Automatic Model-building Program for High-resolution Cryo-Electron Microscopy Maps. Sci Rep 7, 2664, doi:10.1038/s41598-017-02725-w (2017).

42 Emsley, P., Lohkamp, B., Scott, W. G. \& Cowtan, K. Features and development of Coot. Acta Crystallogr. D Biol. Crystallogr. 66, 486-501, doi:10.1107/S0907444910007493 (2010).

43 Afonine, P. V. et al. Real-space refinement in PHENIX for cryo-EM and crystallography. Acta Crystallogr D Struct Biol 74, 531-544, doi:10.1107/S2059798318006551 (2018).

\section{Fig. 1 | Structure of human DUOX1-DUOXA1 complex in the high-calcium state}

a, Schematic of the DUOX enzymatic assay. In the presence of $\mathrm{H}_{2} \mathrm{O}_{2}$ (produced by DUOX), horseradish peroxidase (HRP) converts non-fluorescent Amplex Red to fluorescent resorufin, which is measurable and proportional to $\mathrm{H}_{2} \mathrm{O}_{2}$. 
b, Calcium-dependent activation of hDUOX1-hDUOXA1 complex. Data are shown as means \pm standard deviations, $\mathrm{n}=3$ biologically independent samples.

c, Steady state enzyme activity of hDUOX1-hDUOXA1 complex as the function of NADPH concentration in the presence or absence of calcium. Data were fit to the Michaelis-Menten equation to obtain the $\mathrm{K}_{\mathrm{m}}$ and $\mathrm{K}_{\mathrm{cat}}$ value. Data are shown as means \pm standard deviations, $\mathrm{n}=3$ biologically independent samples.

d, Side view of the cryo-EM map of hDUOX1-hDUOXA1 complex in the high-calcium state. The approximate boundaries of phospholipid bilayer are indicated as gray thick lines. One protomer of hDUOX1 and hDUOXA1 complex is colored as blue and green, the other one is colored as yellow and red, respectively.

e, A $90^{\circ}$ rotated top view compared to $\mathbf{d}$.

f, A $180^{\circ}$ rotated bottom view compared to $\mathbf{e}$.

g, Top view of the cross-section of the transmembrane layer at the position indicated as a dashed line in $\mathbf{d}$. The large cavity in the transmembrane layer is indicated by dashed oval. For clarity, the cryo-EM map was low-pass filtered to $6 \AA$.

h, Topology of hDUOX1 and hDUOXA1 subunits. Transmembrane helices are shown as cylinders, unmodeled disordered regions are shown as dashed lines. The phospholipid bilayer is shown as gray layers. PHD, peroxidase homology domain of hDUOX1; PHLD, pleckstrin homology-like domain of hDUOX1; EF, EF-hand calcium binding module of hDUOX1; DH, dehydrogenase domain of hDUOX1. CLD, claudin-like domain of hDUOXA1.

i, Structure of one protomer of hDUOX1 and hDUOXA1 complex in cartoon representation. The colors of each individual domain are the same as in $\mathbf{g}$. The approximate boundaries of 
phospholipid bilayer are indicated as gray thick lines. Sugar moieties, haems, FAD and NADPH are shown as black, yellow, pink and green sticks, respectively.

\section{Fig. 2 | Structure of hDUOX1 subunit}

a, Side view of hDUOX1 subunit in the high-calcium state, highlighting the key interfaces

(boxed by dashed lines). Each domain is colored as in Fig1h. The surface of hDUOX1 is shown in transparency.

b, The binding site of outer haem in the TMD. Haem is shown as sticks and colored in yellow. Unrelated helices in TMD are omitted for clarity. The putative oxygen-reducing center is indicated by arrow.

c, The binding site of inner haem in the TMD.

d, The interface between PHD and TMD boxed in a. Disulfide bond between C118-C1165 is shown as golden sticks.

e, The interface between PHLD and TMD boxed in a, the hydrogen bonds are indicated with dashed lines.

f, The interface between PHLD and DH domain.

g, The interface between EF module and DH domain.

h, The FAD binding site located at the interface between TMD and DH domain. Ligands and interacting residues are shown as sticks.

i, The NADPH binding site located at the interface between TMD and DH domain.

Fig. 3 | Electron transfer pathway in hDUOX1 subunit in the high-calcium state 
a, The edge-to-edge distances between NADPH and FAD, FAD and inner haem, and two haems are shown beside dashes. The ligands are shown as sticks, each domain of hDUOX are shown in surface, and colored the same as Fig. 1h. Only one hDUOX subunit is shown for clarity. The putative oxygen-reducing center is boxed by dashed lines.

b-e, The close-up view of the putative oxygen-reducing center. Four predicted tunnels for oxygen substrate entrance and product exit are shown as surface in yellow, green, magenta and orange, respectively. Residues surrounding the tunnels are shown as sticks.

f, Calculated radii of tunnels shown in b-e. The putative oxygen-reducing center is used as the starting point for calculation.

\section{Fig. 4 | Mechanism of hDUOX1-hDUOXA1 tetramer assembly}

a, The side view of hDUOX1-hDUOXA1 protein complex shown in surface representation and colored the same as in Fig.1d.

b, The open-book view of the inter-subunit interfaces. Residues of hDUOX1 subunits that interact with hDUOXA1 subunit are colored in green. Residues of hDUOXA1 subunit that interact with hDUOX1 subunits are colored in yellow and blue.

c, The close-up view of the interactions between NTP of hDUOXA1 and hDUOX1 boxed in $\mathbf{a}$.

d, The close-up view of additional interactions between NTP of hDUOXA1 and hDUOX1 boxed in $\mathbf{c}$.

e, The top view of interactions between PHD of two opposing hDUOX1 subunits.

f, Representative FSEC traces of hDOUX1 R50E, R507E and R507A mutants are compared to that of wild-type (WT) hDOUX1. The peak position of the hDOUX1 peak is denoted by the hollow circles. Asterisks denote the peak position of hDUOX1-hDUOXA1 protein complex. 


\section{Fig. 5 | Conformational change of hDUOX1 complex during calcium activation}

a, Structural comparison of hDUOX-hDUOXA1 complex between the high-calcium state (colored) and the low-calcium states (gray). Protein is shown as cartoon. Regions with large conformational changes are boxed by dashed lines.

b, Close-up view of the conformational changes of EF-hand module. C $\alpha$ atom of A894 on $\alpha \mathrm{J}$ helix is used as marker to measure the movement of EF2.

c, Close-up view of the conformational change of PHLD. The angle between $\alpha$ A helices in the high-calcium and low-calcium states was measured.

d-e, Conformational differences of EF-hand module between the high-calcium state and the lowcalcium state.

f, Reconfiguration of the interface between EF-hand module and $\alpha 4$ helix of DH domain. Arrows denote movements from high calcium state into the low-calcium state.

\section{Fig.6 | Activation mechanism of DUOX1 complex by calcium}

Two DUOX1 and one DUOXA1 subunit are shown as cartoon and colored the same as Fig. 1d. Calcium ions are presented as green spheres. Electron transfer pathways are indicted with gray arrows.

\section{Fig. S1 | Biochemical characterization of hDUOX1-hDUOXA1 complex}

a, FSEC traces of three membrane proteins as molecular weight markers. mTPC1-GFP (234 kDa): mouse TPC1 channel with C-terminal GFP; mmKir6.2-MBP-GFP (468 kDa): Mus musculus Kir6.2 channel with C-terminal MBP-GFP; GFP-hTRPC6 (520 kDa): human TRPC6 with N-terminal GFP. 
b, FSEC traces of hDUOX1 and hDUOX1-hDUOXA1 complex. The positions of the molecular weight markers described in a are indicated by arrowheads. hDUOX1: hDUOX1 with Nterminal GFP; hDUOX1+A1: hDUOX1 with N-terminal GFP was coexpressed with nontagged hDUOXA1; hDUOX1+A1-mscarlet: hDUOX1 with N-terminal GFP was coexpressed with hDUOXA1 with C-terminal MBP and mscarlet.

c, Size-exclusion chromatography of hDUOX1-hDUOXA1 peptidisc complex on a superose 6 column. The fractions indicated by dashed lines were used for SDS-PAGE.

d, SDS-PAGE of hDUOX1-hDUOXA1 protein samples. SDS-PAGE (left) of the size-exclusion chromatography fractions labeled in a. Fraction 19 highlighted in red was concentrated for cryoEM sample preparation. SDS-PAGE (right) of hDUOX1-hDUOXA1 protein samples treated with DTT or DTT+PNGase F. The positions of hDUOX1 and hDUOXA1 subunits are indicated by green and black arrows, respectively.

e, UV-Vis spectra of the purified hDUOX1-hDUOXA1 complex. The positions of the Soret peaks are indicated by arrowheads.

f, Activity of the purified hDUOX1-hDUOXA1 complex peptidisc sample in the presence or absence of calcium. Mean \pm s.d., $n=6$ biologically independent samples.

\section{Fig.S2 | Cryo-EM image processing of hDUOX1-hDUOXA1 complex in the high-calcium state}

a, Representative raw micrograph of hDUOX1-hDUOXA1 in the high-calcium state.

b, Representative 2D class averages of hDUOX1-hDUOXA1 in the high-calcium state.

c, The cryo-EM data processing workflow for hDUOX1-hDUOXA1 in the high-calcium state. 
d, The angular distribution for the consensus refinement of hDUOX1-hDUOXA1 in the highcalcium state.

e, Gold-standard FSC curves of hDUOX1-hDUOXA1 in the high-calcium state. Resolution estimations are based on the criterion of FSC 0.143 cutoff.

f, Histogram of the amplitudes along the top eigenvector shows monomodal distribution of hDUOX1-hDUOXA1 in the high-calcium state.

g, Local resolution distribution of the consensus map of hDUOX1-hDUOXA1 in the highcalcium state.

h, Local resolution distribution of the composite map of hDUOX1-hDUOXA1 in the highcalcium state after multibody refinement.

Fig. S3 | Representative electron densities of hDUOX1-hDUOXA1 complex in the highcalcium state

a-b, Representative densities of transmembrane helices of $\mathrm{hDUOX} 1(\mathbf{a})$ and $\mathrm{hDUOXA1(b).}$ c-f, Representative densities of the outer haem with the interacted histidines and spherical density at the putative oxygen-reducing center $(\mathbf{c})$, the inner haem with the interacted histidines (d), FAD (e) and NADPH (f).

g-h, Representative densities of PHLD (g), EF module (h). Models of hDuox1 and hDuoxA1 are colored the same as in Fig. 1h. The representative densities are all shown in blue mesh. Electron density maps are all contoured at $\sigma=1.86$.

Fig. S4 | Cryo-EM image processing of hDUOX1-hDUOXA1 complex in the high-calcium state 
a, Representative raw micrograph of hDUOX1-hDUOXA1 in the low-calcium state.

b, Representative 2D class averages of hDUOX1-hDUOXA1 in the low-calcium state.

c, The cryo-EM data processing workflow for hDUOX1-hDUOXA1 in the low-calcium state.

d, The angular distribution for the consensus refinement of hDUOX1-hDUOXA1 in the lowcalcium state.

e, Gold-standard FSC curves of hDUOX1-hDUOXA1 in the low-calcium state. Resolution estimations are based on the criterion of FSC 0.143 cutoff.

f, Histogram of the amplitudes along the top eigenvector of hDUOX1-hDUOXA1 in the lowcalcium state shows a plateau-shaped distribution compared to that of the high-calcium state. g, Local resolution distribution of the consensus map of hDUOX1-hDUOXA1 in the low calcium state.

h, Local resolution distribution of the composite map of hDUOX1-hDUOXA1 in the low calcium state after multibody refinement.

Fig. S5 | Sequence alignment of the peroxidase homology domain (PHD) of DUOX. The sequences of the Homo sapiens DUOX1 (hDUOX1), Homo sapiens DUOX2 (hDUOX2), Danio rerio DUOX (drDUOX), Drosophila melanogaster DUOX (dmDUOX) and Caenorhabditis elegans DUOX (ceDUOX) were aligned. Residues following PHD are omitted for clarity. The sequence alignment of Figs. S5-8 are all shown as follows: Conserved residues are highlighted in gray; Secondary structures are indicated as cylinders ( $\alpha$ helices), arrows ( $\beta$ sheets) and lines (loops); Unmodeled residues are indicated as dashed line; The color of arrows and cylinders are the same as in Fig. 1h. Residues of cation binding site 1 (CBS1) and cation 
binding site 2 (CBS2) are indicated as black circles and violet circles, respectively. The filled circles and empty circles indicate side chain and main chain interactions.

Fig. S6 | Sequence alignment from M0 helix to transmembrane domain (TMD) of DUOX. The sequences of the Homo sapiens DUOX1 (hDUOX1), Homo sapiens DUOX2 (hDUOX2), Danio rerio DUOX (drDUOX), Drosophila melanogaster DUOX (dmDUOX), Caenorhabditis elegans DUOX (ceDUOX) and Cylindrospermum stagnale NOX5 (csNOX5) were aligned. Residues belonging to PHD are shown in violet, and residues following TMD are omitted for clarity. Residues predicted to be responsible for calcium binding in EF1 and EF2 are indicated as black diamonds and orange diamonds, respectively. The filled diamonds and empty diamonds indicate side chain and main chain interactions. Histidines coordinating the outer haem and the inner haem are enclosed by black boxes and blue boxes, respectively. Residues of proposed oxygen substrate binding site are indicated as asterisks.

Fig. S7 | Sequence alignment of the dehydrogenase domain (DH) of DUOX. The sequences of the Homo sapiens DUOX1 (hDUOX1), Homo sapiens DUOX2 (hDUOX2), Danio rerio DUOX (drDUOX), Drosophila melanogaster DUOX (dmDUOX), Caenorhabditis elegans DUOX (ceDUOX) and Cylindrospermum stagnale NOX5 (csNOX5) were aligned. Residues belonging to TMD are shown in marine. Conserved residues are highlighted in gray. Secondary structures are indicated as cylinders ( $\alpha$ helices), arrows ( $\beta$ sheets) and lines (loops). Unmodeled residues are indicated as dashed line. The color of arrows and cylinders are the same as in Fig. 1. 
Fig. S8 | Sequence alignment of DUOXA. The sequences of the Homo sapiens DUOXA1

The sequences of the Homo sapiens DUOXA1 (hDUOXA1), Homo sapiens DUOXA2

(hDUOXA2), Danio rerio DUOXA2 (drDUOXA2), Drosophila melanogaster DUOXA

(dmDUOXA) and Caenorhabditis elegans DUOXA1 (ceDUOXA1) were aligned. Conserved

residues are highlighted in gray. C-terminal residues are omitted for clarity. Secondary structures are indicated as cylinders ( $\alpha$ helices), arrows ( $\beta$ sheets) and lines (loops). Unmodeled residues are indicated as dashed lines. The color of arrows and cylinders are the same as in Fig. 1.

\section{Fig. S9 | Structure of hDUOX1 PHD domain}

a, Structural comparison between hDUOX1 PHD (pink) and DdPoxA (PDB ID: 6ERC, gray). CBS1 and CBS2 are denoted by arrows.

b, Electron densities of CBS1 and CBS2 in the high-calcium state and low-calcium states.

c, CBS1 and CBS2 in DdPoxA (PDB ID: 6ERC).

d, FSEC profiles showed mutations of hDUOX1 CBS1 (T322A, D379A) or CBS2 (D109A, D174A) affect hDUOX1-hDUOXA1 tetramer assembly. Asterisks denote the peak position of tetrameric complex and circles denote hDUOX1 monomer peak position.

\section{Fig. S10 | Structure of hDUOX1 TMD and cytosolic domains}

a, Structural comparison between hDUOX1 TMD (blue) and csNOX (PDB ID: 5O0T, gray). The putative oxygen-reducing center is shown as red sphere.

b, The close-up view of the similar architecture of the putative oxygen-reducing center.

c, Structural comparison between hDUOX1 PHLD (light blue) and PDZ-RhoGEF (PDB

ID:3KZ1, gray). 
d, Structural comparison between hDUOX1 EF module (orange) and Calcineurin B subunit (PDB ID: 4IL1, gray).

e, Calcium binding on EF1 domain. Calcium ion is modeled according to 4IL1 and shown as green sphere.

f, Calcium binding on EF2 domain. Calcium ion is modeled according to 4IL1 and shown as green sphere.

g, Structure of hDUOX1 EF module (orange) in complex with $\alpha 4$ helix (light blue) of DH domain.

h, Structure of calcineurin B subunit in complex with helix of calcineurin A subunit (PDB ID: 4IL1).

i, Structural comparison of NADPH binding pocket between hDUOX1 (colored) and csNOX (PDB ID: 5O0X, gray). Only $\beta 13$ and NADPH are shown for clarity.

j, Structural comparison of FAD binding pocket between hDUOX1 (colored) and csNOX (PDB ID: 5O0X, gray). The large rotations of adenosine group of FAD are denoted by arrows.

\section{Fig. S11| Structure of hDUOXA1 subunit}

a, Structure of hDUOXA1 subunit with secondary structure labeled.

b, Structural comparison of hDUOXA1 with claudin-9 (PDB ID:6OV2). hDUOXA1 is colored in green and claudin-9 is colored in gray, respectively.

\section{Movie S1| Structural changes of the cytosolic domains of hDUOX1-hDUOXA1 complex during calcium activation}


hDUOUX1-hDUOXA1 complex is shown as cartoon and colored the same as Fig.1h. Calcium ions are shown as green spheres. The movie starts from the whole molecule and then focuses on the cytosolic domains of one protomer. The structural changes are presented as a morph between the high-calcium state and the low-calcium state. 
bioRxiv preprint doi: https://doi.org/10.1101/2020.09.23.309245; this version posted September 23, 2020. The copyright holder for this preprint (waich was not certified by peer review) is the althor/funder, who has granted bioRxiv a lioense to display the preprint in perpetuity. It is made
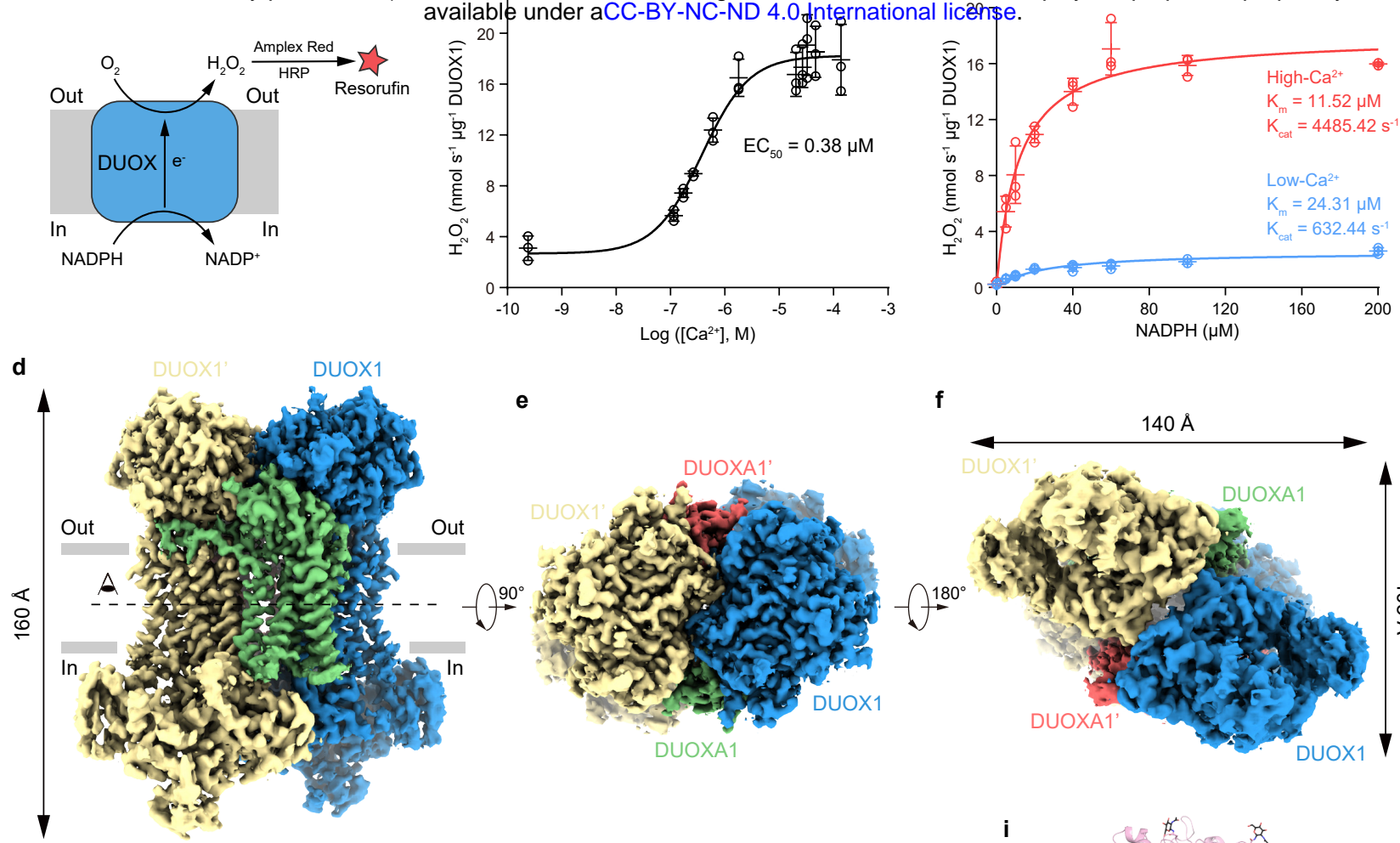

e

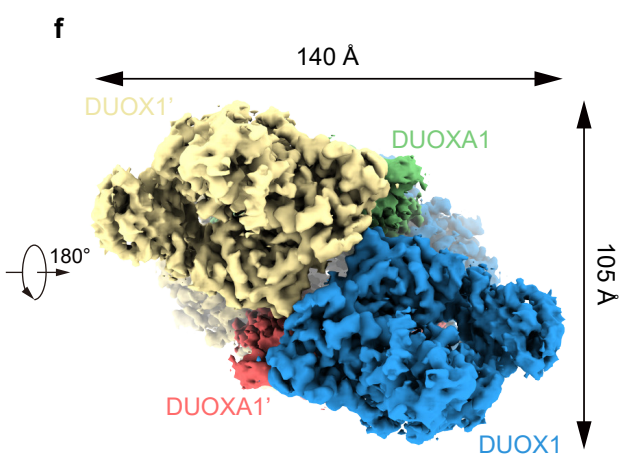

g

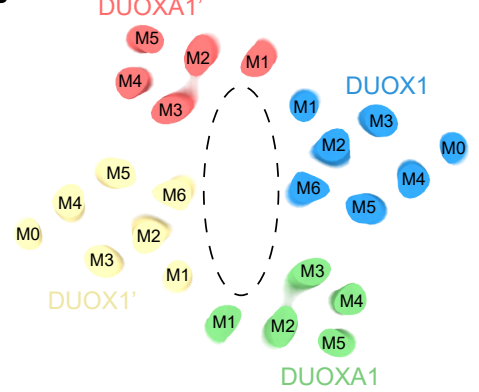

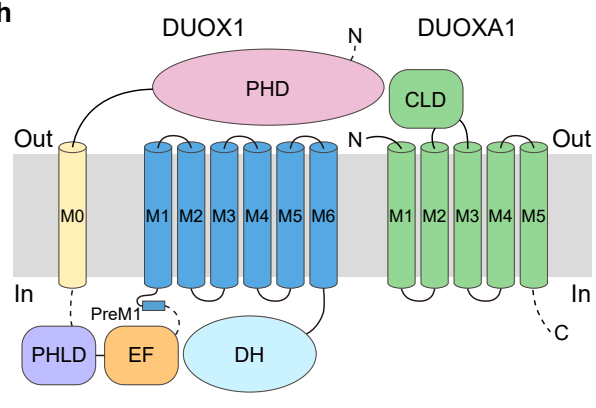

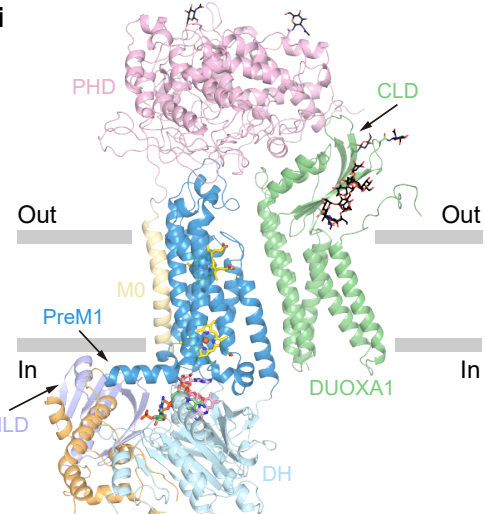

क 3

Fig. 1 
bioRxiv preprint doi: https://doi.org/10.1101/2020.09.23.309245; this version posted September 23, 2020. The copyright holder for this preprint (which was not certified by peer review) is the author/funder, who has granted bioRxiv a license to display the preprint in perpetuity. It is made available under aCC-BY-NC-ND 4.0 International license.

a

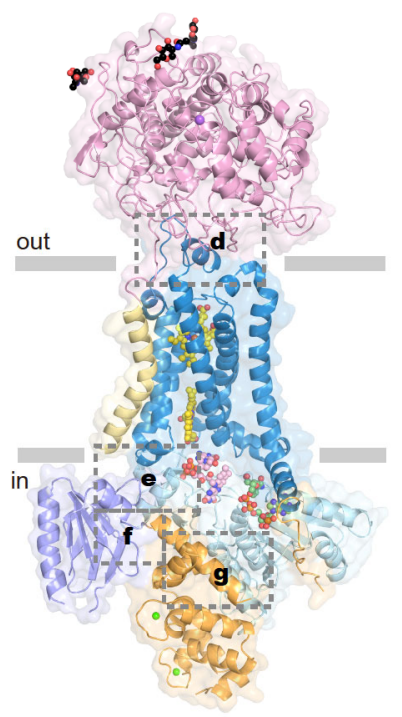

d

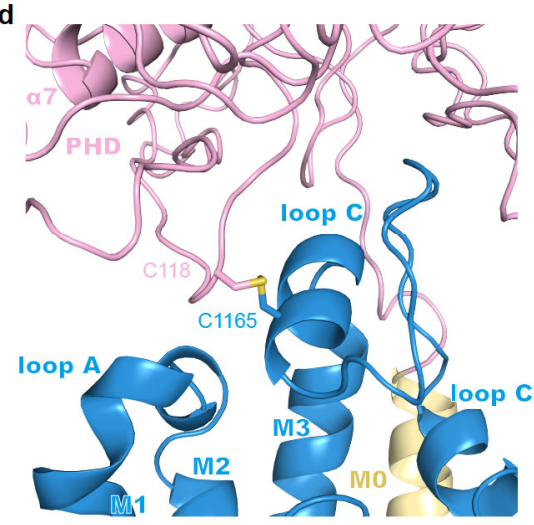

b

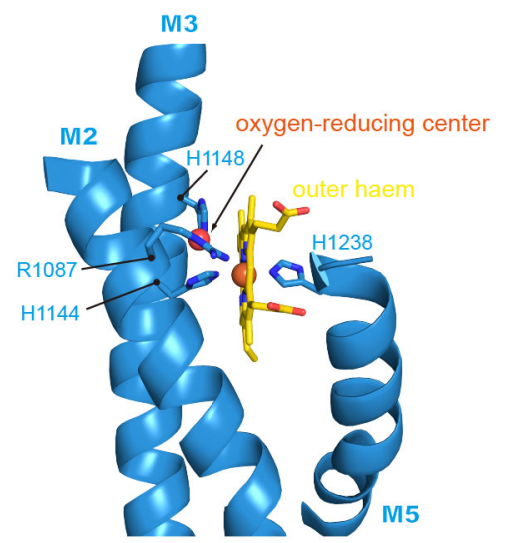

e

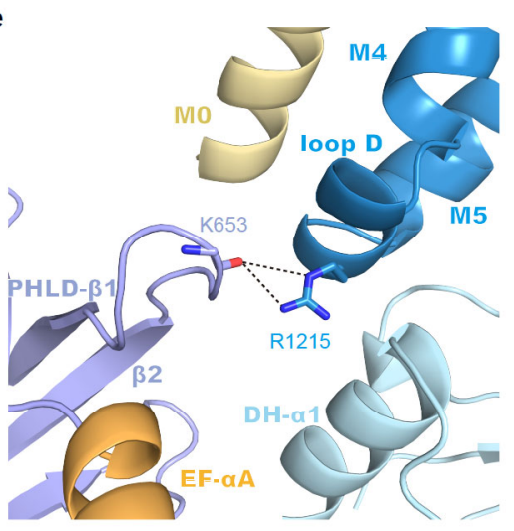

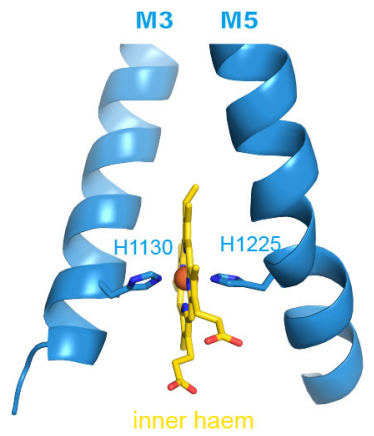

g

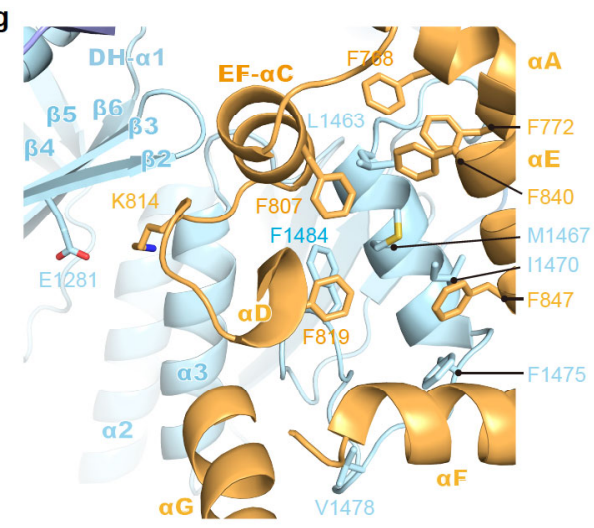

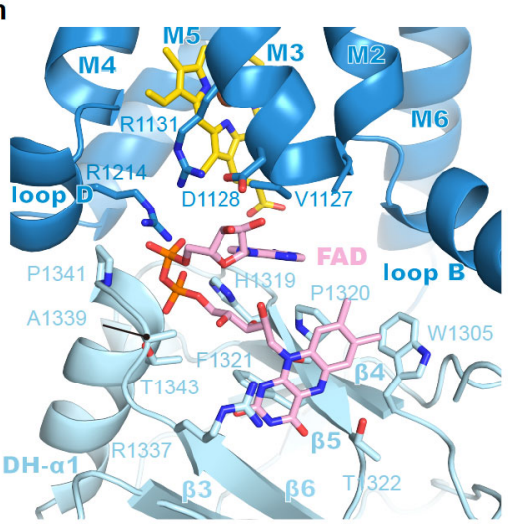
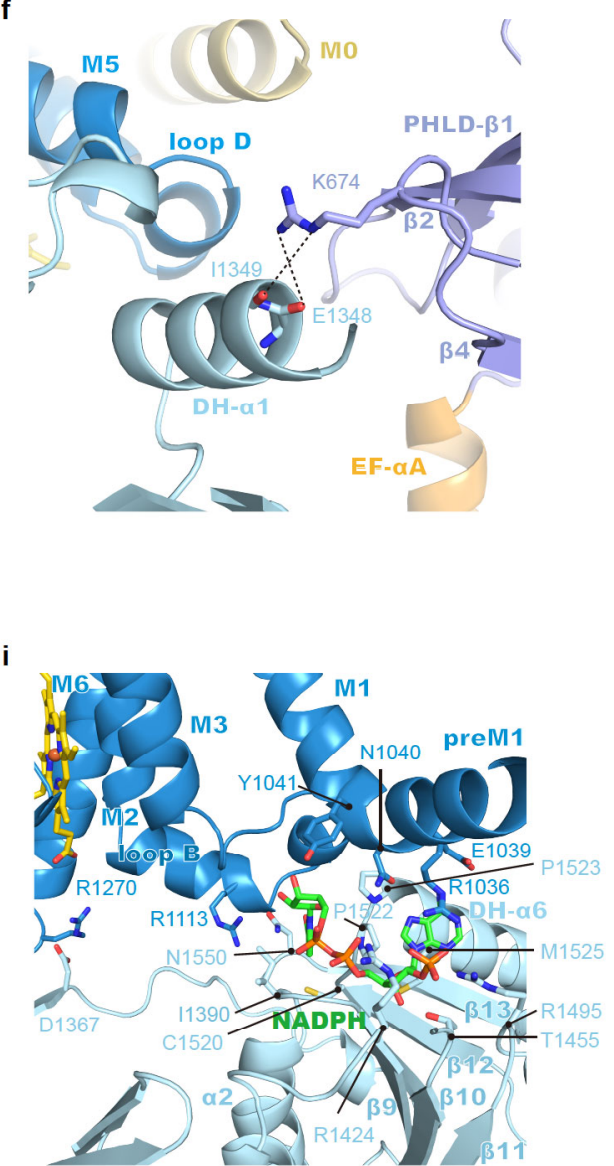

Fig. 2 


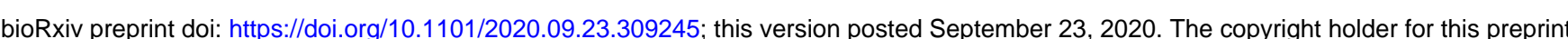
(which was not certified by peer review) is the author/funder, who has granted bioRxiv a license to display the preprint in perpetuity. It is made available under aCC-BY-NC-ND 4.0 International license.

a

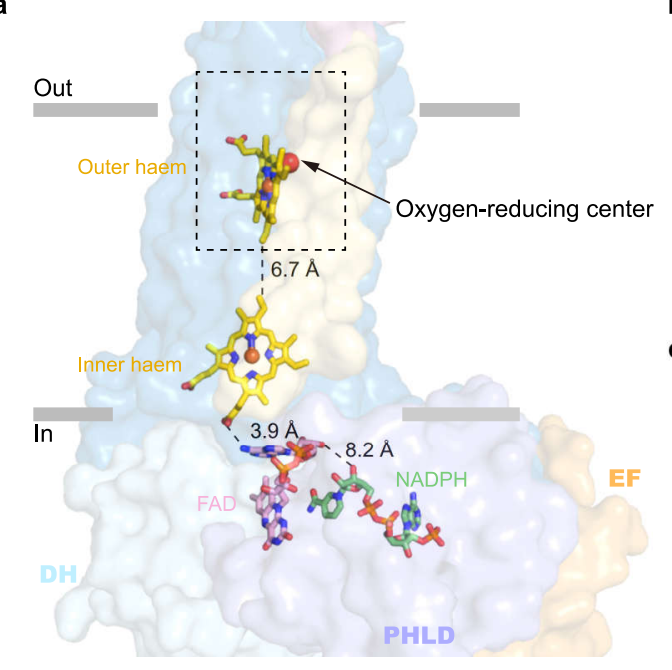

b

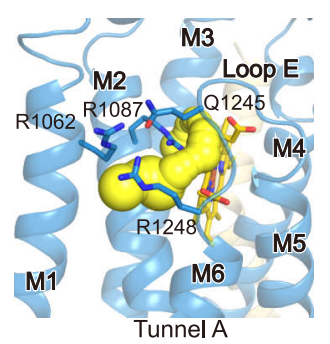

c

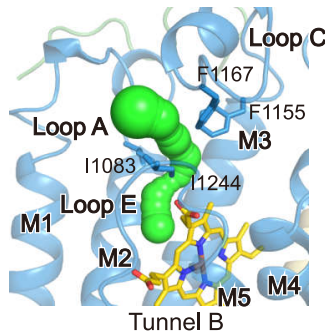

d

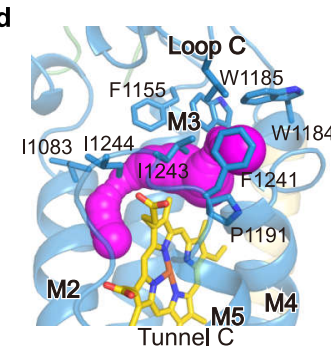

e

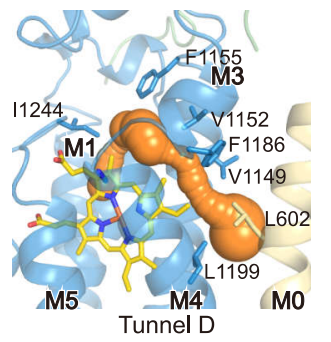

f

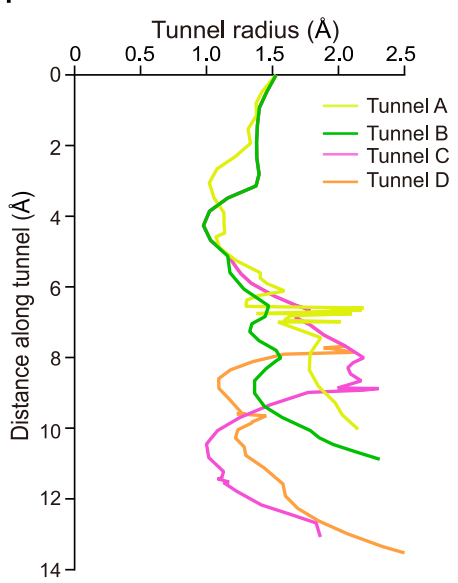

Fig. 3 
bioRxiv preprint doi: https://doi.org/10.1101/2020.09.23.309245; this version posted September 23, 2020. The copyright holder for this preprint (which was not certified by peer review) is the author/funder, who has granted bioRxiv a license to display the preprint in perpetuity. It is made
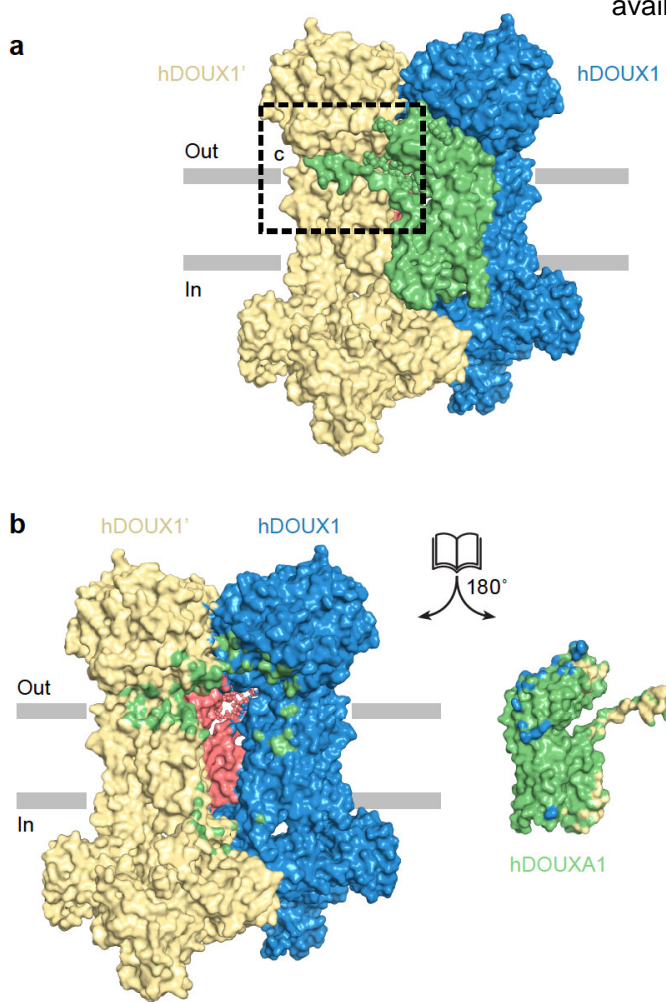

c

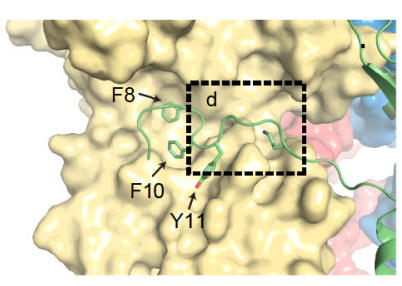

d
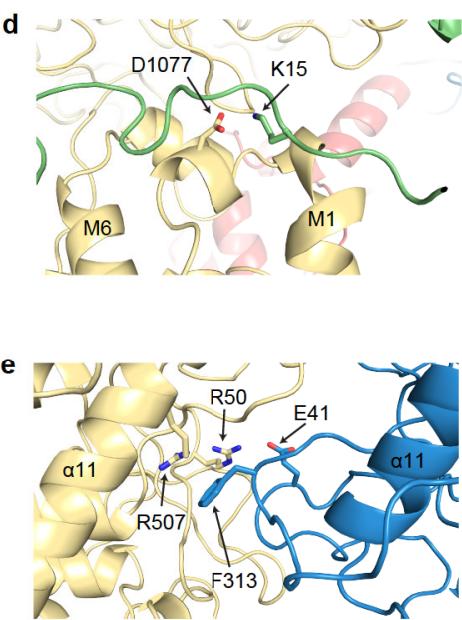
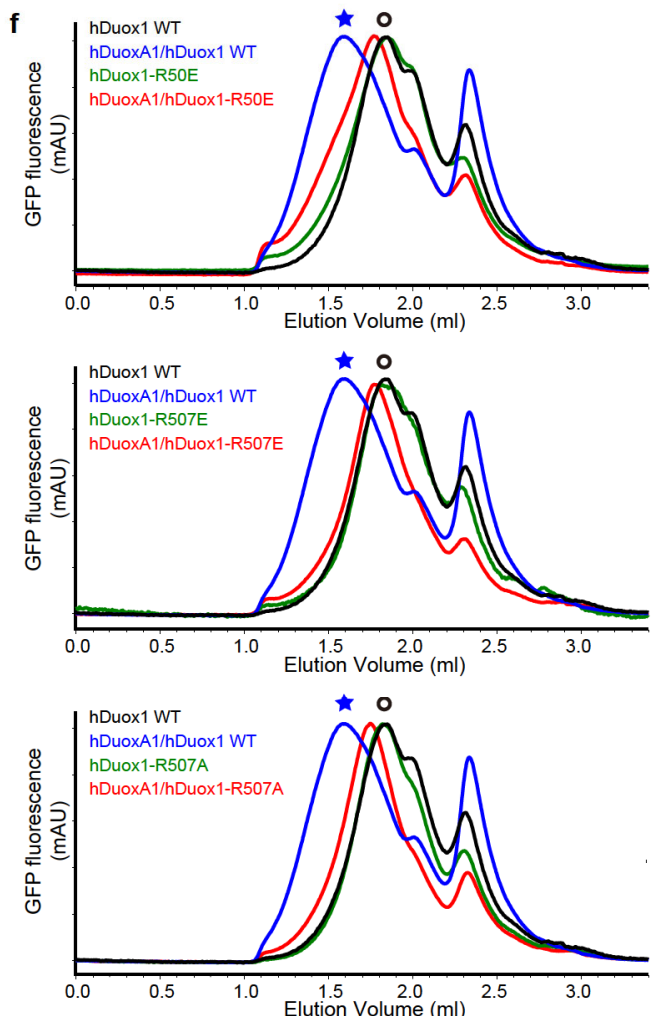

Fig. 4 
bioRxiv preprint doi: https://doi.org/10.1101/2020.09.23.309245; this version posted September 23, 2020. The copyright holder for this preprint (which was not certified by peer review) is the author/funder, who has granted bioRxiv a license to display the preprint in perpetuity. It is made available under aCC-BY-NC-ND 4.0 International license.

a

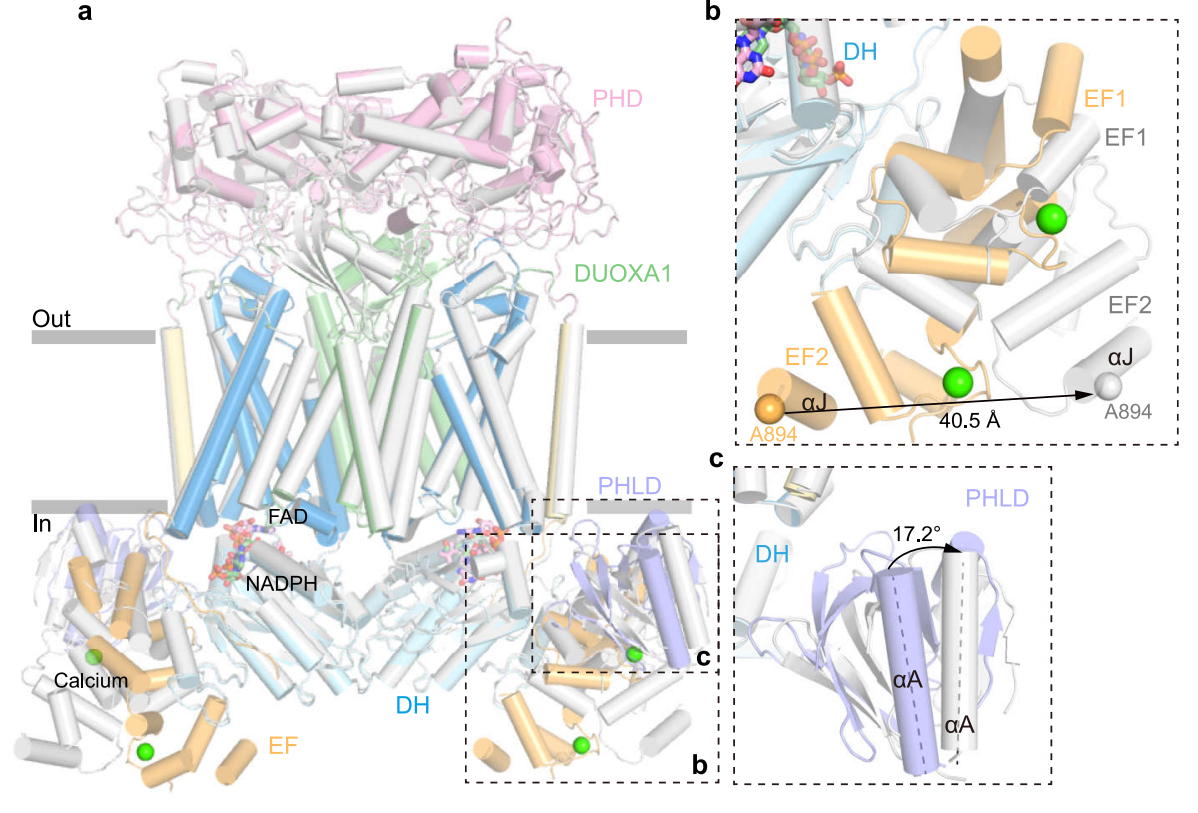

d

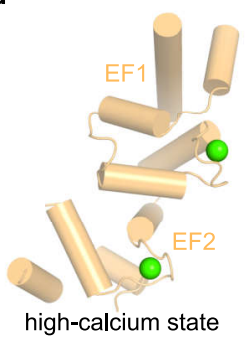

f

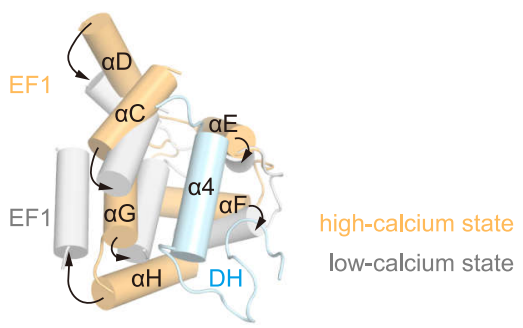

Fig. 5 
bioRxiv preprint doi: https://doi.org/10.1101/2020.09.23.309245; this version posted September 23, 2020. The copyright holder for this preprint (which was not certified by peer review) is the author/funder, who has granted bioRxiv a license to display the preprint in perpetuity. It is made available under aCC-BY-NC-ND 4.0 International license.
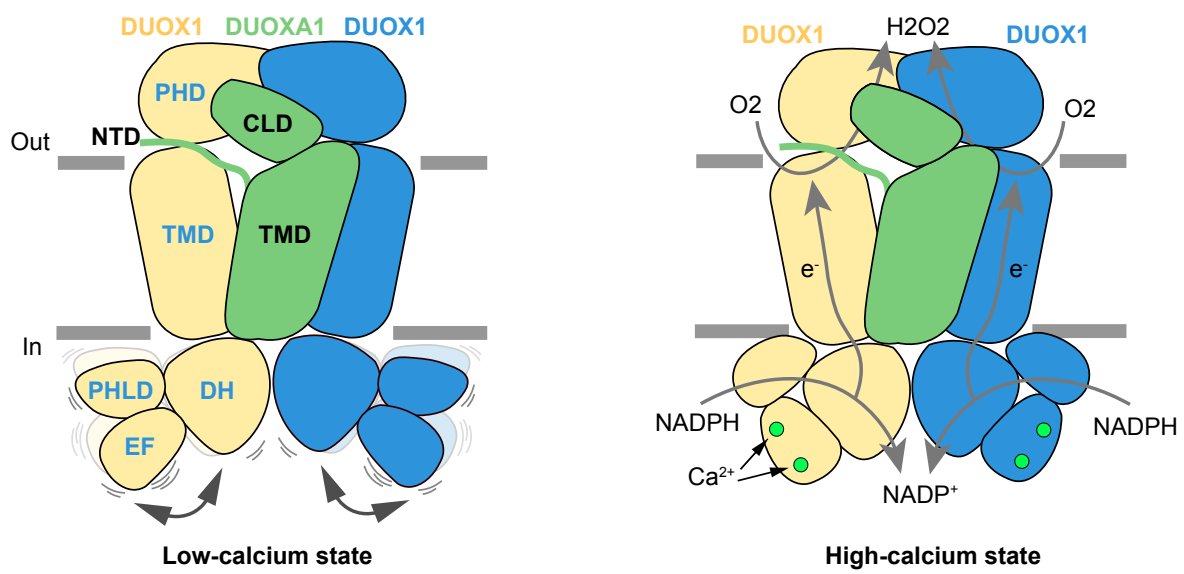

Fig. 6 
bioRxiv preprint doi: https://doi.org/10.1101/2020.09.23.309245; this version posted September 23, 2020. The copyright holder for this preprint (which was not certified by peer review) is the author/funder, who has granted bioRxiv a license to display the preprint in perpetuity. It is made available under aCC-BY-NC-ND 4.0 International license.

a

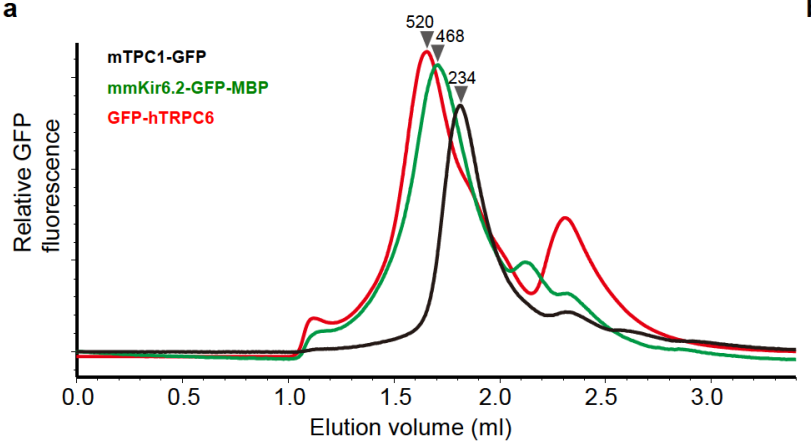

C

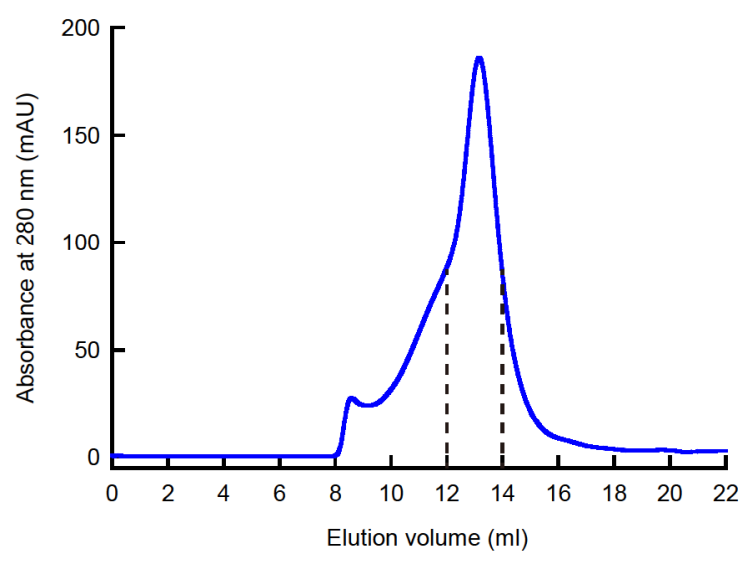

e

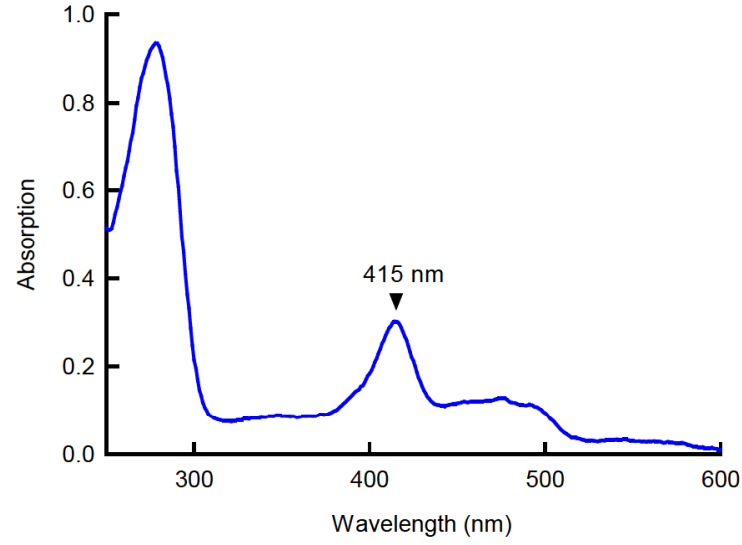

$\mathbf{f}$
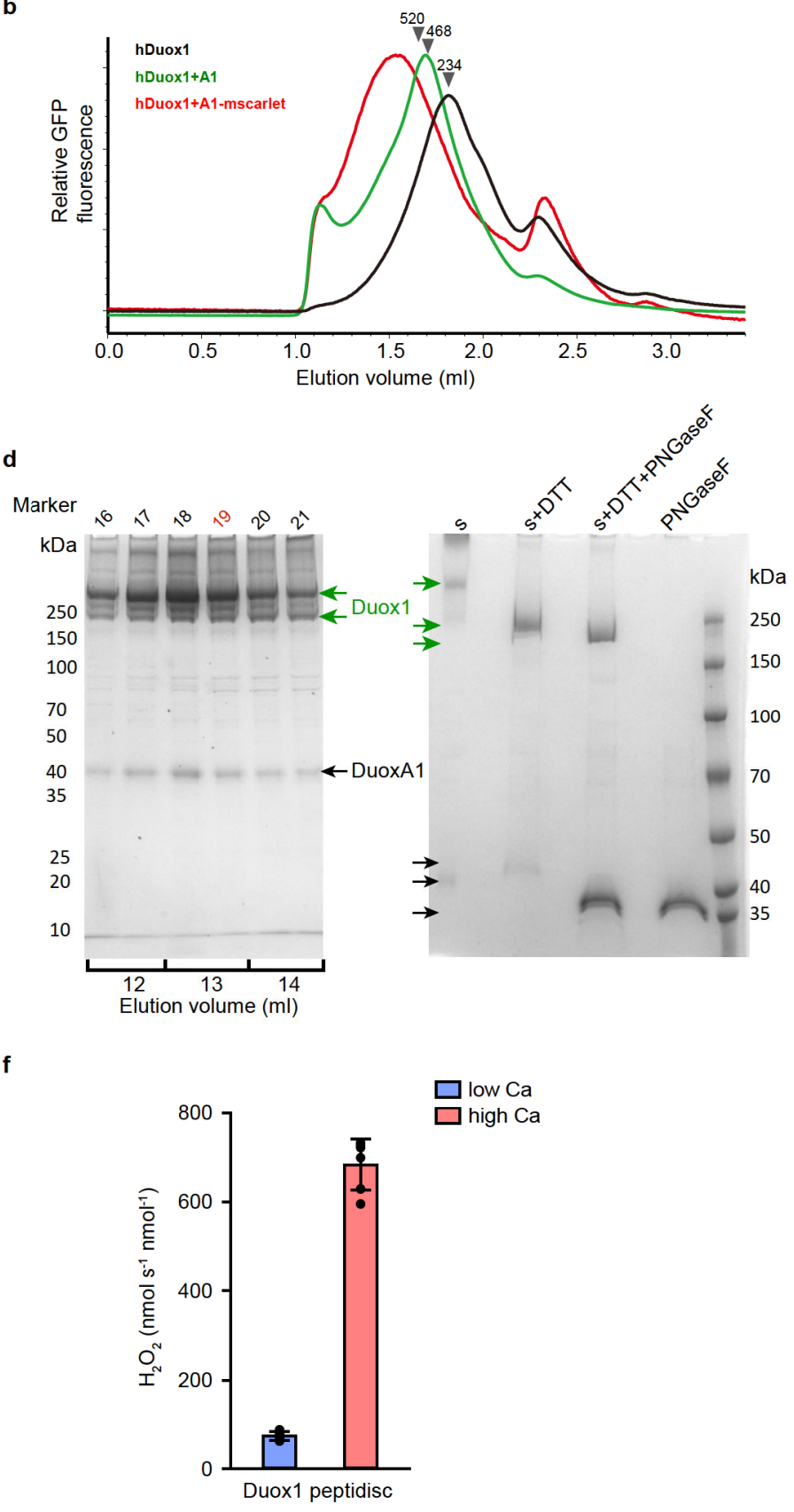

Fig. $\mathbf{~} 1$ 
bioRxiv preprint doi: https://doi.org/10.1101/2020.09.23.309245; this version posted September 23, 2020. The copyright holder for this preprint (which was not certified by peer review) is the author/funder, who has granted bioRxit a lieenso to display the preprint in perpetuity. It is made
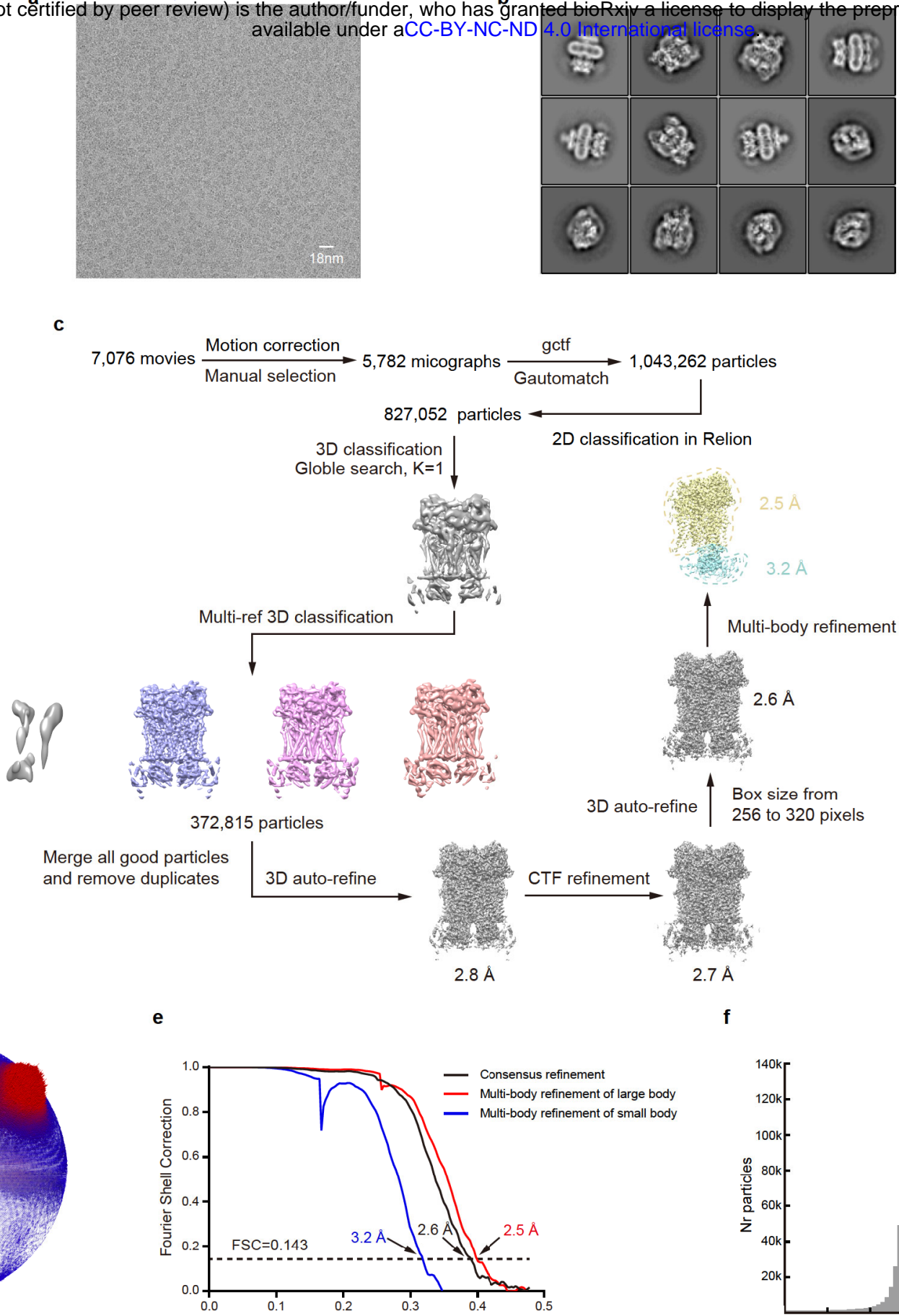

$3 \mathrm{D}$ classification Globle search, $\mathrm{K}=1$

2D classification in Relion
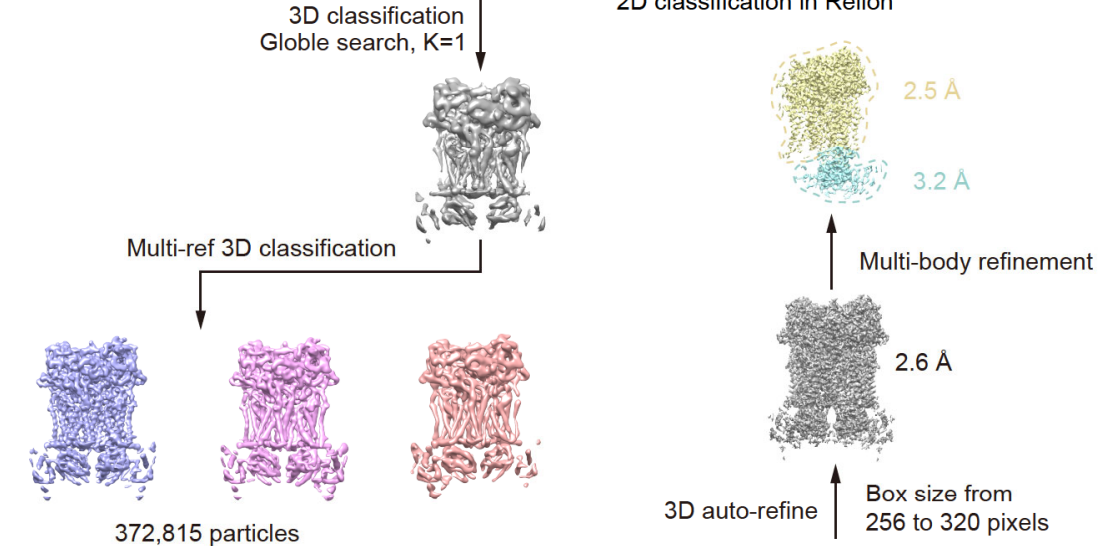

Merge all good particles and remove duplicates
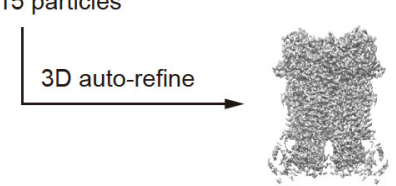

CTF refinement

$2.8 \AA$

d

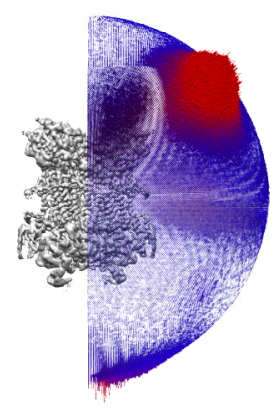

e

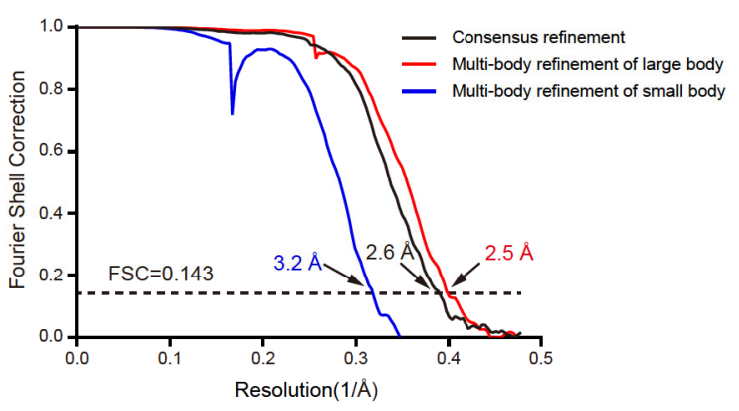

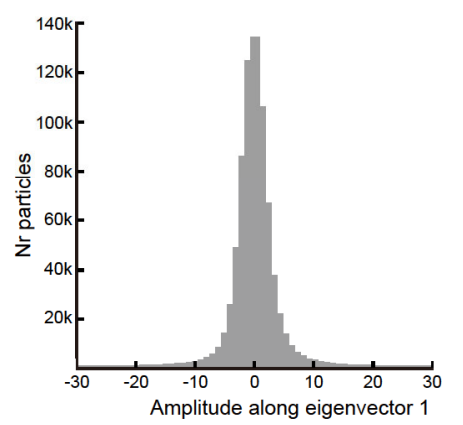

g

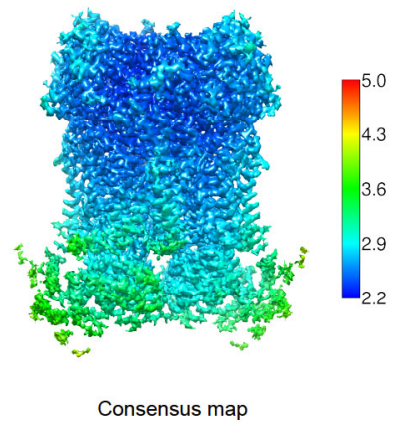

h

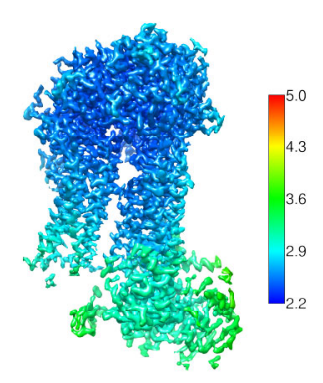

After multibody refinement

Fig. S2 
a bioRxiv preprint doi https:/doi.org/10.1101/2020.09.23.309245, this version posted September 23 , 2020 . The copyright holder for this preprint
(which was not cekified by peer review) is the author/funder, who has granted bioRxiv a license to display the preprint in perpetuity. It is made

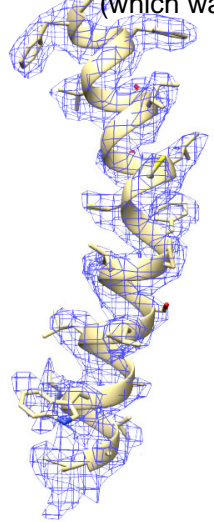

MO

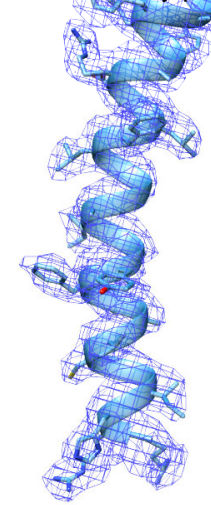

M1

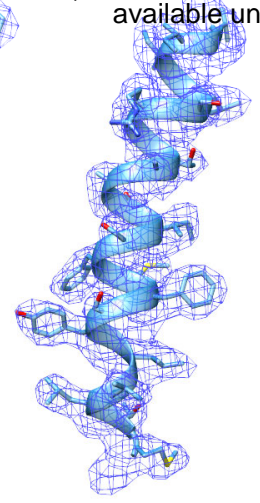

M2

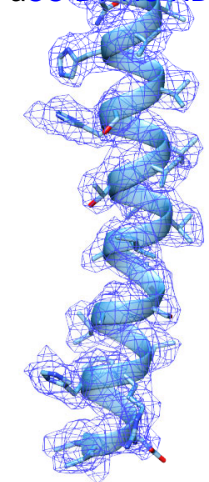

M3

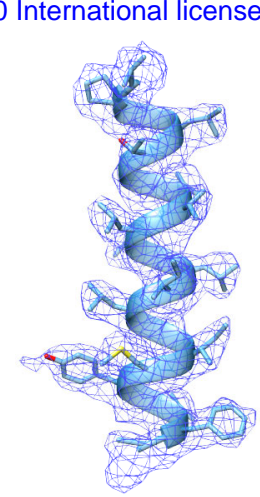

M4

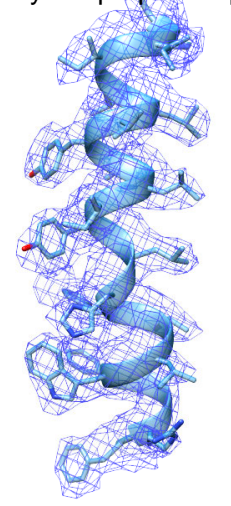

M5

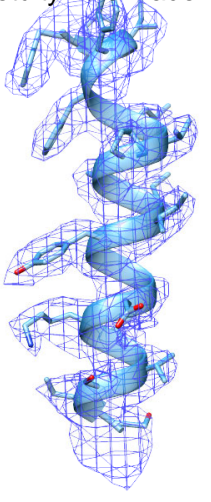

M6

b

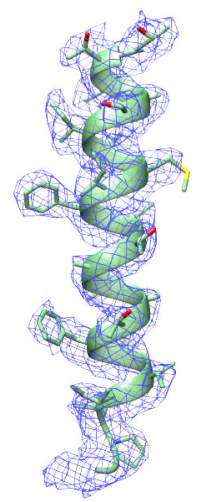

M1

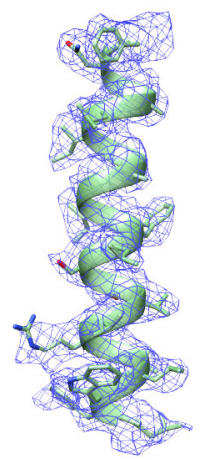

M2

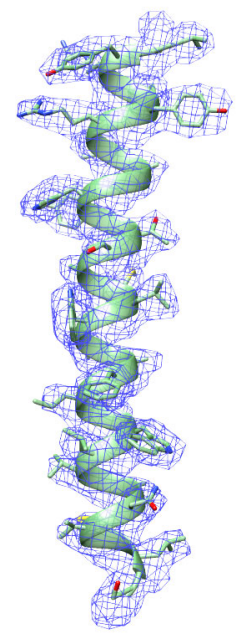

M3

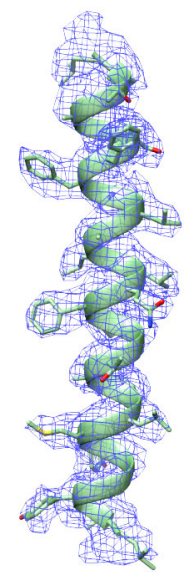

$\mathrm{M} 4$

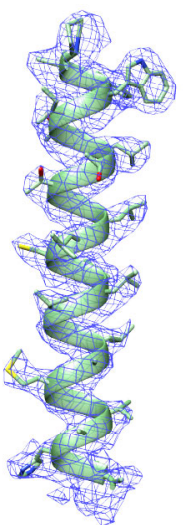

M5

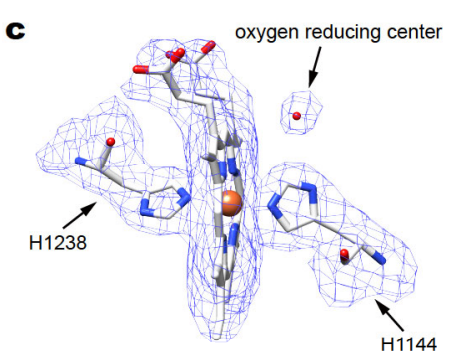

outer haem + oxygen

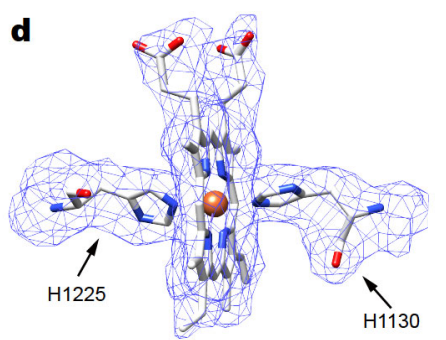

inner haem

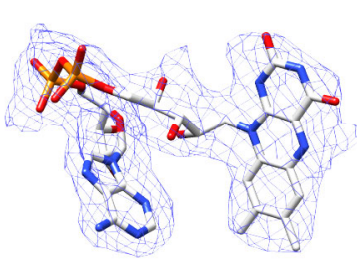

f

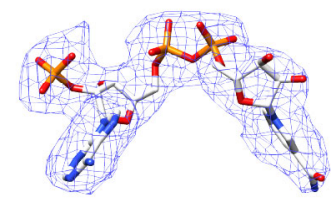

FAD

NADPH

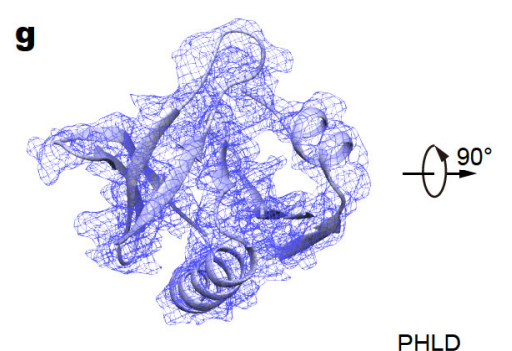

PHLD

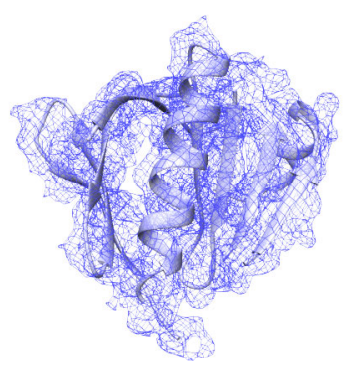

h

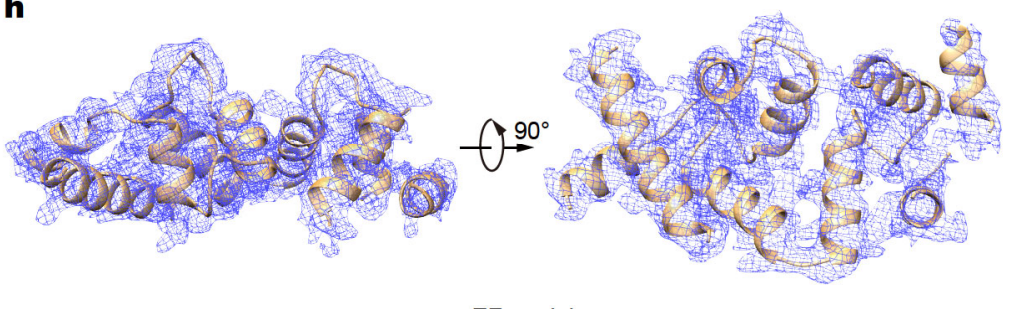

EF module

Fig. S3 
bioRxiv preprint doi: https://doi.org/10.1101/2020.09.23.309245; this version posted September 23, 2020. The copyright holder for this preprint (which was not certified by peer review) is the author/funder, who has granted bioRxiv a license to display the preprint in perpetuity. It is made available under aCC-BY-NC-ND 4.0 International license.

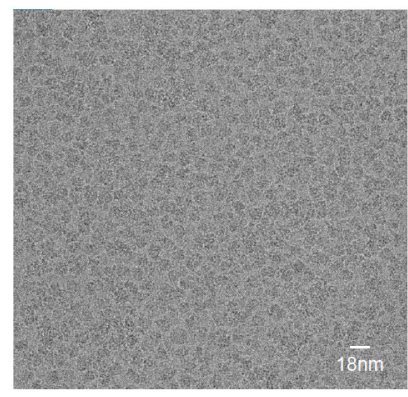

b

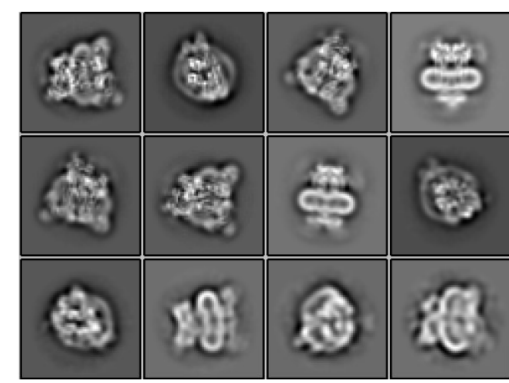

c

$$
2,076 \text { movies } \underset{\text { Manual selection }}{\stackrel{\text { Motion correction }}{\longrightarrow}} 1,997 \text { micographs } \underset{\text { Gautomatch }}{\longrightarrow} 783,802 \text { particles }
$$

Multi-ref 3D classification $\begin{gathered}3 \mathrm{D} \text { classification } \\ \text { Globle search, } \mathrm{K}=1\end{gathered} \quad$ 2D classification in Relion

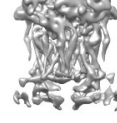

318,466 particles
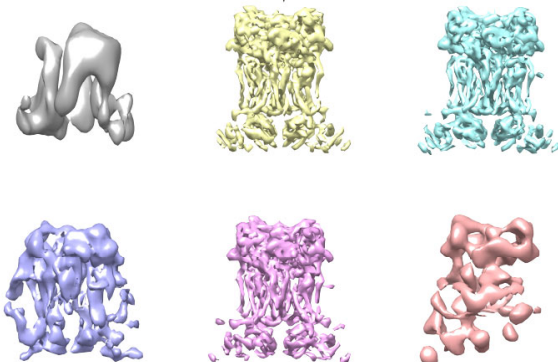

Merge all good particles and remove duplicates
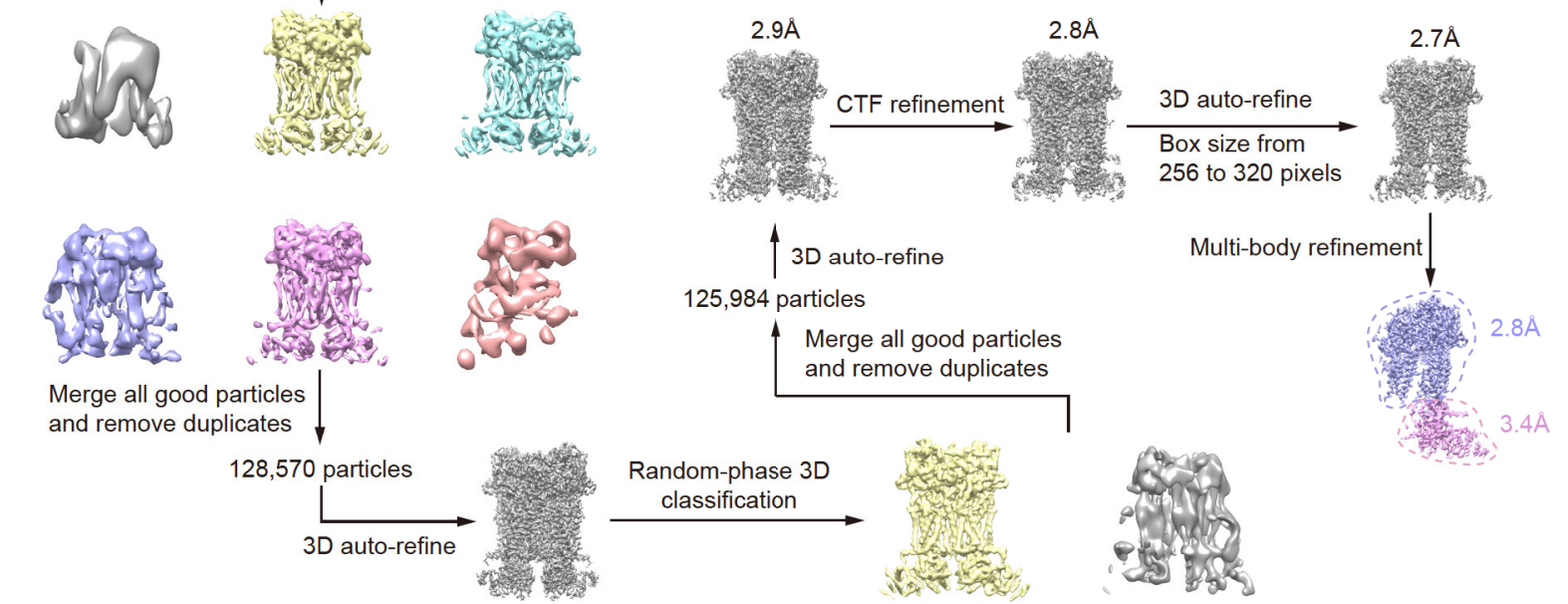

Merge all good particles and remove duplicates
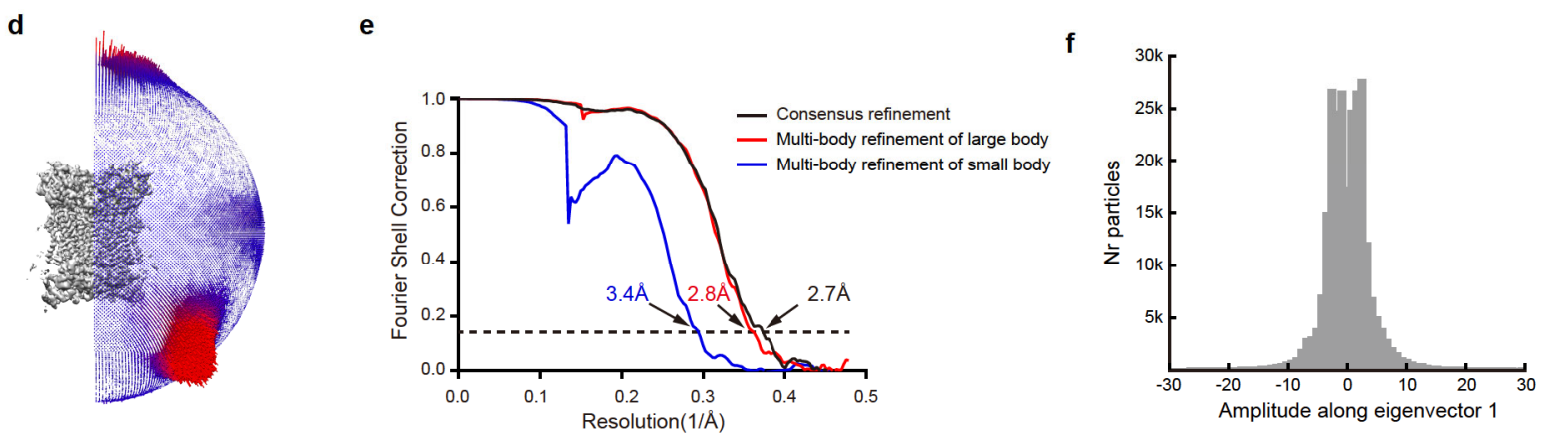

g

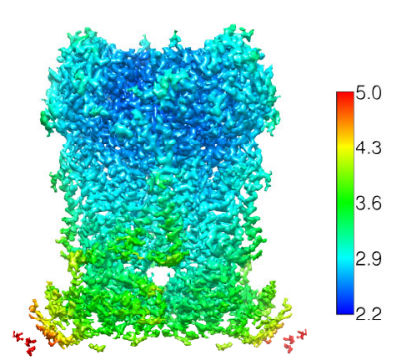

Consensus map h

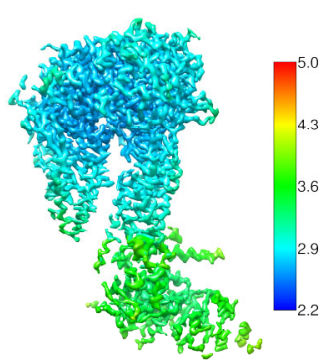

After multibody refinement

Fig. S4 
bioRxiv preprint doi: https://doi.org/10.1101/2020.09.23.309245; this version posted September 23, 2020. The copyright holder for this preprint (which was not certified by peer review) is the author/funder, who has granted bioRxiv a license to display the preprint in perpetuity. It is made available under aCC-BY-NC-ND 4.0 International license.

\title{
DUOX PHD
}

$\begin{array}{ll}\text { hDUOX1 } & 1 \\ \text { hDUOX2 } & 1 \\ \text { drDUOX } & 1 \\ \text { dmDUOX } & 1 \\ \text { ceDUOX } & 1\end{array}$

hDUOX1 29 hDUOX2 35 drDUOX 34 dmDUOX 69 ceDUOX

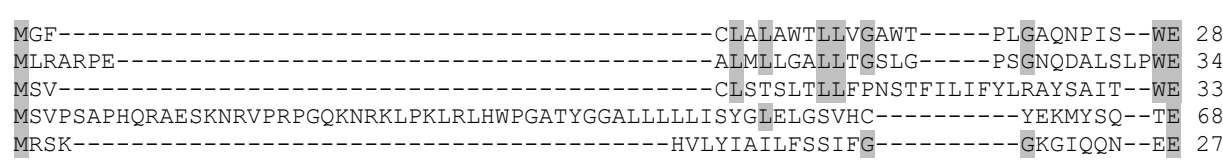

MRSK--

$\alpha 1$

$\alpha 2$

\begin{abstract}
VQREDGWYNNLMEHRWGSKGSRLQRLVPASYADGVYQPLGEPHLPNPRDLSNTISRGPAGLASLRNRTVLGVFFGYHVLS 108 VQRYDGWFNNLRHHERGAVGCRLQRRVPANYADGVYQALEEPQLPNPRRLSNAATRGIAGLPSLHNRTVLGVFFGYHVLS 114 VQRYDGWYNNLADHDRGAADASLVRLYPAQYMDGVYLARQEPHLPNPRRISTTAMSGQSGLLSHKNRSVLSVAFGYHVWS 113 KQRYDGWYNNLAHPDWGSVDSHLVRKAPPSYSDGVYAMAGA-NRPSTRRLSRLFMRGKDGLGSKFNRTALLAFFGQLVAN 147 FQRYDGWYNNLANSEWGSAGSRLHRDARSYYSDGVYSVNN--SLPSARELSDILFKGESGIPNTRGCTTLLAFFSQVVAY 105
\end{abstract}

Q

hDUOX1 109 DLVSVETPGCPAEFLNIRIPPGDPMFDPDQRGDVVLPFQRSRWDPETGRSPSNPRDPANQVTGWLDGSAIYGSSHSWSDA 188 hDUOX2 115 DVVSVETPGCPAEFLNIRIPPGDPVFDPDQRGDVVLPFQRSRWDPETGRSPSNPRDLANQVTGWLDGSAIYGSSHSWSDA 194 drDUOX 114 EISESRRAGCPPEFMHIKVQKDDPVFVSNSSQPVLLQFQRADWDTSTGKSPNNPRTQVNHVTAWIDGSSIYGSSSSWSDA 193 dmDUOX 148 EIVMASESGCPIEMHRIEIEKCDEMYDRECRGDKYIPFHRAAYDRDTGQSPNAPREQINQMTAWIDGSFIYSTSEAWLNA 227 CEDUOX 106 EIMQSNGVSCPLETLKIQVPLCDNVFDKECEGKTEIPFTRAKYDKATGNGLNSPREQINERTSWIDGSFIYGTTQPWVSS 185

$\alpha 3$

hDUOX1 189 LRSFSRGQLASGPDPAFPRDSNPLLMW-AAPDPATG-QNGPRGLYAFGAERGNREPFLQALGLLWFRYHNLWAQRLARQ 266 hDUOX2 195 LRSFSGGQLASGPDPAFPRDSQNPLLMW-AAPDPATG-QNGPRGLYAFGAERGNREPFLQALGLLWFRYHNLWAQRLARQ 272 drDUOX 194 LREFSGGRLSSSSSRDMPRRSSNGYLMW-SSPDPSSGPDSGSQELYEFGNAWANENIFSVTEGIIWFRYHNYLASKLHKE 272 dmDUOX 228 MRSFHNGTLLTEKDGKLPVRNTMRVPLFNNPVPSVMK-MLSPERLFLLGDPRTNQNPAILSFAILFLRWHNTLAQRIKRV 306 CEDUOX 186 LRSFKQGRLAEGVPGYPPLN-NPHIPLNNPAPPQVHR-LMSPDRLFMLGDSRVNENPGLLSFGLILFRWHNYNANQIHRE 263
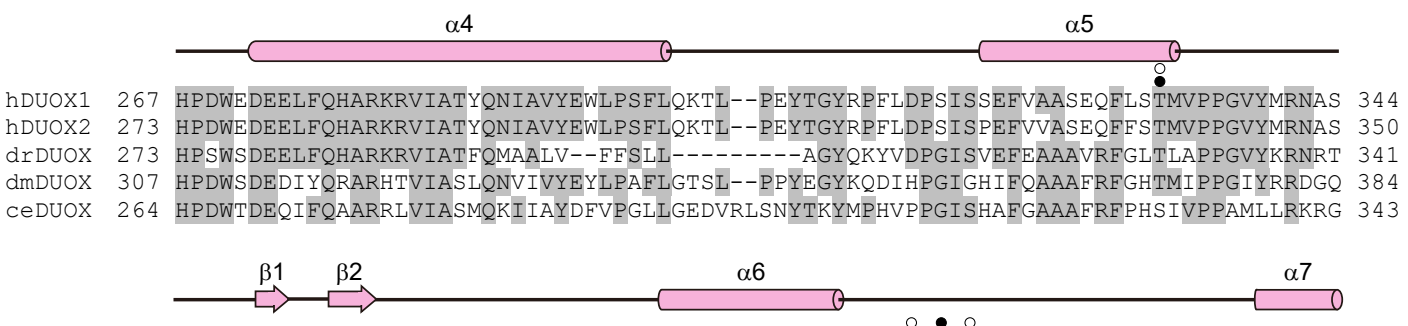

hDUOX1 345 CHFQGVINRNSSVSRALRVCNSYWSREHPSLQSAEDVDALLLGMASQIAEREDHVLVEDVRDFWPGPLKFSRTDHLASCL 424 hDUOX2 351 CHFRKVLNKGFQSSQALRVCNNYWIRENPNLNSTQEVNELLLGMASQISELEDNIVVEDLRDYWPGPGKFSRTDYVASSI 430 drDUOX 342 CHYRSVVNDDASKSPGLRLCNTFWNRNNPHLQSSLDVDELIMGMASQIAEREDNIIVEDLRDYMYGPLRFSRSDAVALTI 421 dmDUOX 385 CNFKET----PMGYPAVRLCSTWWDSSGF--FADTSVEEVLMGLASQISEREDPVLCSDVRDKLFGPMEFTRRDLGALNI 458 CEDUOX 344 NKCEFR--TEVGGYPALRLCQNWWNAQDI--VKEYSVDEIILGMASQIAERDDNIVVEDLRDYIFGPMHFSRLDVVASSI 419

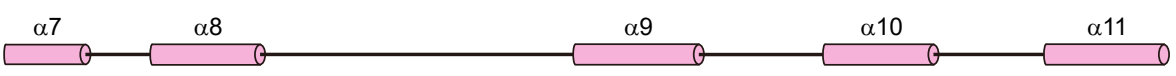

hDUOX1 425 QRGRDLGLPSYTKARAALGLSPITRWQDINPALSRSNDTVLEATAALYNQDLSWLELLPGGLLESHR-DPGPLFSTIVLE 503 hDUOX2 431 QRGRDMGLPSYSQALLAFGLDIPRNWSDLNPNV---DPQVLEATAALYNQDLSQLELLLGGLLESHG-DPGPLFSAIVLD 506 drDUOX 422 QRGRDFGLPSYNQIREALSMAPVNSFEDINPKL---KDTKL---ADLYENDISRLELFVGGLLETQE-GPGPVFSTIILD 494 dmDUOX 459 MRGRDNGLPDYNTARESYGLKRHKTWTDINPPLFETQPELLDMLKEAYDNKLDDVDVYVGGMLESYG-QPGEFFTAVIKE 537 CEDUOX 420 MRGRDNGVPPYNELRRTFGLAP-KTWETMNEDFYKKHTAKVEKLKELYGGNILYLDAYVGGMLEGGENGPGELFKEIIKD 498

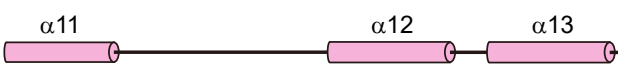

hDUOX1 504 QFVRLRDGDRYWFENTRNGLFSKKEIEEIRNTTLQDVLVAVINIDPSALQPNVFVWHKGDPCPQPRQLSTEGLPACAPSV 583 hDUOX2 507 QFVRLRDGDRYWFENTRNGLFSKKEIEDIRNTTLRDVLVAVINIDPSALQPNVFVWHKGAPCPQPKQLTTDGLPQCAPLT 586 drDUOX 495 QFERIRNADRFWFENKQNGLFTEEEIKAIRNTTFHDVLLHVTSAEKGDIQRSVFFWKNGDPCPQPQPIRASDLQPCTKAF 574 dMDUOX 538 QFQRLRDADRFWFENERNGIFTPEEIAELRKITLWDIIVNSTDVKEEEIQKDVFMWRTGDPCPQPMQLNATELEPCTYLE 617 CEDUOX 499 QFTRIRDGDRFWFENKLNGLFTDEEVQMIHSITLRDIIKATTDIDETMLQKDVFFFKEGDPCPQPFQVNTTGLEPCVPFM 578

hDUOX1 584 VRDYFEGS 591

hDUOX2 587 VLDFFEGS 594

drDUOX 575 SMSYFDDS 582

dmDUOX 618 GYDYFSGS 625

ceDUOX 579 QSTYWTDN 586

\section{Fig.S5}


bioRxiv preprint doi: https://doi.org/10.1101/2020.09.23.309245; this version posted September 23, 2020. The copyright holder for this preprint

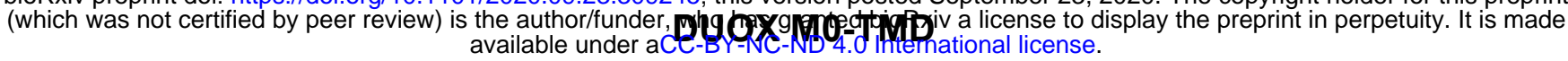

Mo $\beta A$

$\begin{array}{ll}\text { hDUOX1 } & 584 \\ \text { hDUOX2 } & 587 \\ \text { drDUOX } & 575 \\ \text { dmDUOX } & 618 \\ \text { ceDUOX } & 579 \\ \text { csNOX5 } & 1\end{array}$

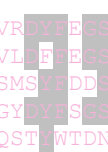
G-FGFGVTIGTLCCFPLVSLLSAWIVARLRMRNFKRLQGQDR------QSIVSEKLVGGMEALEWQGHKEPC 656 S-PGFAITIIALCCLPLVSLLLSGVVAYFRGREHKKLQKKLK------ESVKKEAAKDGVPAMEWPGPKERS 659 SKVGFGVTVVVLFLFPVGQ---SSAVAQVRTARFKRFQQKRS------GSTKHKEPAHGTTASEWLGHNTAP 645 E-LMF IYVCVF LGFVPI LCAGAGYCVVKLQNSKRRRLKIRQE----ALRAPQHKGSVDKMLAREWLH-ANHK 691 D-TTYVFTLIGLACVPLICYGIGRYLVNRRIAIGHNSACDS LTTDFANDDCGAKGDIYGVNALEWLQ-EEY I 656 CeDUOX 579 $\stackrel{B \mathrm{~B}}{\mathrm{BC}} \sim$

hDUOX1 657 RPVLVYLQPGQ-IRVVDGRLTVLRTIQLQPPQKVNFVLSSN----RGRRTLLLKIPKEYDLVLLFNLEEERQALVENLRG 731 hDUOX2 660 SPIIIQLLSDRCLQVLNRHLTVLRVVQLQPLQQVNLILSNN----RGCRTLLLKIPKEYDLVLLFSSEEERGAFVQQLWD 735 drDUOX 646 RQVTLAFSEKKVFQTFDENGSPLSSHSLGNQDHLNVIVSND----HQHRALLLKIPKEYDLVLFFEDGVQRSEFLSLLRS 721 dmDUOX 692 RLVTVKFGPEAAIYTVDRKGEKLRTFSLKHIDVVSVEESATN-HIKKKPYILLRVPSDHDLVLELESYGARRKFVKKLED 770

$\begin{array}{lll}\text { CeDUOX } & 657 & \text { RQVRIEIE-NTTLAVKKPRGGILRKIREETGQKIELFHSMPNPSAMHGPFVLISQKNNHHLVIRLSSDRDLSKFLDQIRQ } 735 \\ \text { CSNOX5 } & 1 & \end{array}$ CSNOX5 1

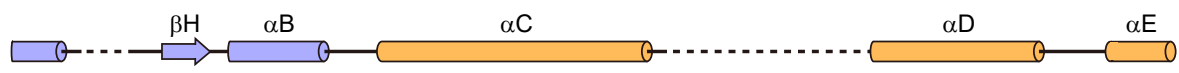

hDUOX1 732 hDUOX2 736 drDUOX 722 $\begin{array}{ll}\text { dmDUOX } & 771 \\ \text { CeDUOX } & 736\end{array}$ CeDUOX 736

ALKESGLSIQEWELREQELMRAAVTREQRRHLLETFFRHLFSQVLDINQADAGTLPLDSSQKV---REALTCELSRAEFA 808 FCVRWALGLHVAEMSEKELFRKAVTKQQRERILEIFFRHLFAQVLDINQADAGTLPLDSSQKV---REALTCELSRAEFA 812 ELEGRIQSLTVMEKSEKEMLCDAVTREQRGKIVETFFKHAFSKVLDIDKSDAG----DLSSRT---REALQCELTRAEFA 794 FLLLHKKEMTLMEVNRDIMLARAETRERRQKRLEYFFREAYALTFGLR--PGERRRRSDASSDGEVMTVMRTSLSKAEFA 848 AASGINAEVI IKDEENSI LLSQAITKERRQDRLDLFFREAYAKAFNDS--ELQDSETSFDSSN---DDILNETISREELA 810 -------------GLLTVLSLK YHNEFLTEIEINI I--VDTPKK--TLEELRRVFTQIA-----KEDKQI DQAEFK 55

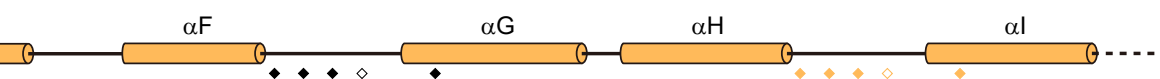

hDUOX1 809 ESLGLKPQDMFVESMFSLADKDGNGYLSFREFLILVVFMKGSPEEKSRLMFRMYDFDGNGLISKDEFIRMLRSFIEISN 888 hDUOX2 813 ESLGLKPQDMFVESMFSLADKDGNGYLSFREFLDILVVFMKGS PEDKSRLMFTMYDLDENGFLSKDEFFTMMRSFIEISN 892 drDUOX 795 SVLGLKSDSLFVESMFTLADKDGNGYLSFQEFLDVIVIFMTGTSEEKSKLLFSTHDIKGDGFLSKEEFTSLLRSFIDIS- 873 dmDUOX 849 AALGMKPNDMFVRKMFNIVDKDQDGRISFQEFLETVVLFSRGKTDDKLRI IFDMCDNDRNGVIDKGELSEMMRSLVEIAR 928 CEDUOX 811 SAMGMKANNEFVKRMFAMTAKHNEDSLSFNEFLTVLREFVNAPOKOKLOTLFKMCDLEGKNKVLRKDLAELVKSLNOTAG 890 CSNOX5 56 SALGLK-DEYFVDRLFSIFDTDSSGTIKIEEFLTTVENLVFATSEEKLQFAYELHDVNGDGCIEKAEISHLITASLKENN 134 Q $Q \ldots \ldots \ldots$

hDUOX1 888 -NCLSKAQLAEVVESMFRESGF-QDKEELTWEDFHFMLRDHNSELR-------FTQLCVK-----GVEVPEVIK-DLCRR 953 hDUOX2 892 -NCLSKAQLAEVVESMFRESGF-QDKEELTWEDFHFMLRDHDSELR-------FTQLCVKGGGGGGNGIRDIFKQNISCR 963 drDUOX 873 -GALSKSQADDGIAAMLQTAGL-YNKDRFSWEDFHFLLRDHSAQLNIKGQEILFLPLC-----------RDIF--SLPNT 938 dmDUOX 929 TTSLGDDQVTELIDGMFQDVGL-EHKNHLTYQDFKLMMKEYKGDFV-------AIGLDCK-----GAKQNFLD------- 988 CEDUOX 890 -VHITESVQLRLFNEVLHYAGVSNDAKYLTYDDFNALFSDIPDKQP-------VGLPFNR-----KNYQPSIG------- 950 CSNOX5 134 -LSFSPEQINELVDLLFREADA-DKSGEISFAEFKGLIEKFPDLIE-------AMTVSPI------SWLK---------- 189

hDUOX1 954 ASYISQDMICPSPRVSARCSRSDIETELT PQRLQCPMDTDPP---QEIRRRFGKKVTSFQPLLFTEAHREKFQRSCLHQT 1030 hDUOX2 964 VSFITRT---PGERSH-------------PQGLGPPAPEAPELGGPGLKKRFGKKAAVPTPRLYTEALQEKMQRGFLAQK 1027 drDUOX 939 EVFYTATIIYFCSSSS-----SVEELTHTPE---------EEHGQELRQRAGQS----QAKLYVRPQRERFNRNPVQQC 999 dmDUOX 988 --------------

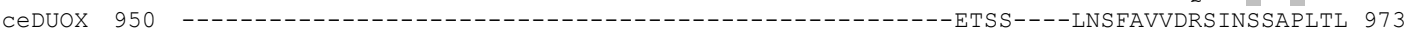
CSNOX5 189 -

PreM1 M1 LoopA M2

hDUOX1 1031 VQQFKRFIENYRRHIGCVAVFYAIAGGLFLERAYYYAFAAHHTGITDTTRVGIILSRGTAASISFMFSYILLTMCRNLIT 1110 $\begin{array}{lllll}\text { hDUOX1 } & 1031 & \text { VQEKRFIENYRRHIGCVAVFYAIAGGLFLERAYYYAFAAHHTGITDTTRVGIILSRGTAASISFMFSYILLTMCRNLIT } 1110 \\ \text { hDUOX2 } & 1028 \text { LQQYKRFVENYRRHIVCVAIFSAICVGVFADRAYYYGEASPPSDIAQTTLVGIILSRGTAASVSFMFSYILLTMCRNLIT } 1107\end{array}$ drDUOX 1000 VQQFKRF IENYRRHI ICTVVIYAISAGLALERC IYYGLQAHSSGIPETSMVGVLVSRGSAAAISELFPYMLLTVCRNLIT 1079 dmDUOX 1016 WDAYITELEENRQNIFYLFLFYVVTIVLFVERF I HYSFMAEHTDLRH IMGVGIAITRGSAASLSFCYSLLLLTMSRNLIT 1095 CEDUOX 974 IHKVSAFLETYRQHVFIVFCFVAINLVLFFERFWHYRYMAENRDLRRVMGAGIAITRGAAGALSFCMALILLTVCRNIIT 1053 CSNOX5 208 KAYIKYYIENNWVKIAFLALYVFVNMFFFMSAVEKYES-------QGANLYVQIARGCGATLNLNGALILIPMLRHFMT 279

M3 LoopB

hDUOX1 1111 FLRETFLNRYVPFDAAVDFHRLIASTAIVLTVI $\stackrel{*}{*}$ * * *VVVVVYLFSISPLSVLSCLFPGLFHDDGSEFPQKYYWWFFQTV 1190 hDUOX2 1108 FLRETFLNRYVPFDAAVDFHRWIAMAAVVLAII HSAGHAVNVYIFSVSPLSLLACIFPNVFVNDGSKLPQKFYWWFFQTV 1187 drDUOX 1080 MCRETFLNRYIPFDAAIDI HRQMAATALILSVVESLGHLVNVYIFCISDLSILACLFPKVF SNNGSELPMKWTEWFFKTV 1159 dmDUOX 1096 KLKEFPIQQYIPLDSHIQFHKIAACTALFFSVI HVGHIVNFYHVSTQSHENLRCLTREVHFAS--DYKPDITFWLFQTV 1173 CEDUOX 1054 LLRETVIAQYIPFDSAIAFHKIVALFAAFWATI HTVGCVNFYHVGTQSQEGLACLFQEAFFGS--NFLPSISYWFFSTI 1131 CSNOX5 280 WLRKTTINNYIPIDESIEFHKLVGQVMFALAIVHIGAHFLNYTTLP---------------------IPFAQSLFGTK 336

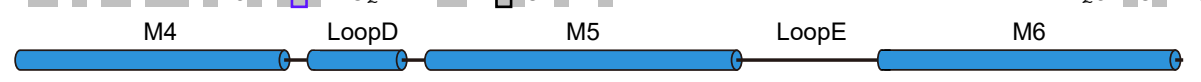

hDUOX1 1191 PGLTGVVLLLILAIMYVFASHH-FRRRSFRGFWLTHHLYILLYVLLIIFGSFALIQLPRFHIFFLVPAIIYGGDKLVSLS 1269 hDUOX2 1188 PGMTGVLLLLVLAIMYVFASHH-FRRRSFRGFWLTHHLYILLYALLIIHGSYALIQLPTFHIYFLVPAIIYGGDKLVSLS 1266 drDUOX 1160 PGITGVILLLIFAFMYVFASHY-FRRISFRGFWITHHLYVLIYV-LVI HGSYGLLQQPRFHIYLI P G GLLELDKLISLS 1237 dmDUOX 1174 TGTTGVMLFI IMCI I FVFAHPT-IRKKAYNFFWNM HITY IGLYLLSLI GLARLTGPPRFWMFFLGPGIVYTLDKIVSLR 1252 CEDUOX 1132 TGLTGIALVAVMCIIYVFALPC-FIKRAYHAFRLTHLLNIAFYALTLIHGLPKLLDSPKFGYYVVGPIVLFVIDRIIGLM 1210 CSNOX5 337 AGISGELLLLVEIIMWVTAQAPIRKGGKFALFYIAHMGYVLWFALALI HG-------PVEWQWVLLPVVGEI IELVIRWK 409 
bioRxiv preprint doi: https://doi.org/10.1101/2020.09.23.309245; this version posted September 23, 2020. The copyright holder for this preprint (which was not certified by peer review) is the author/funder, who has granted bioRxiv a license to display the preprint in perpetuity. It is made available under aCC-BY-NC-ND 4.0 International license.

\section{DUOX DH}

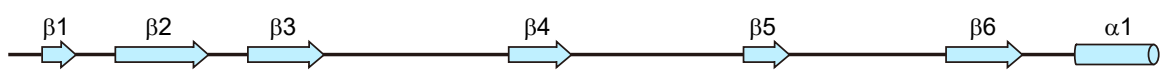

hDUOX1 1270 RKKVEISVVKAELLPSGVTHLRFQRPQGFEYKSGQWVRIACLALGT--TEYHPFTLTSAPH-EDTLSLHIRAAGPWTTRL 1346 hDUOX2 1267 RKKVEISVVKAELLPSGVTYLQFQRPQGEEYKSGQWVRIACLALGT--TEYHPFTLTSAPH-EDTLSLHIRAVGPWTTRL 1343 drDUOX 1238 RKKVEIPVLKAELLPSDVTMLEFKRPQGEVYRSGQWVRIACLTLGT--DEYHPFTLTSAPH-EETLSLHIRAAGPWTSKL 1314 dmDUOX 1253 TKYMALDVIDTDLLPSDVIKIKFYRPPNLKYLSGQWVRLSCTAFRP--HEMHSFTLTSAPH-ENFLSCHIKAQGPWTWKL 1329 CEDUOX 1211 OYYKKLEIVNAEILPSDI IYIEYRRPREFKYKSGQWVTVSSPSISCTFNESHAFS IASSPQ-DENMKLYIKAVGPWTWKL 1289 CSNOX5 410 TTKEPTFVVNASLLPSKVLGLQVQRPQSENYQPGDYLFIKCPGISK--FEWHPFTISSAPEMPDVLTLHIRAVGSWTGKL 487

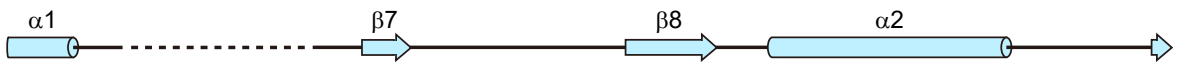

hDUOX1 1347 REIYSAPT-------GDRCARYPKLYLDGPFGEGHQEWHKFEVSVLVGGGIGVTPFASILKDLVFKSSVS--CQVFCKKI 1417 hDUOX2 1344 REIYSSPK-------GNGCAGYPKLYLDGPFGEGHQEWHKFEVSVLVGGGIGVTPFASILKDLVFKSSLG--SQMLCKKI 1414 drDUOX 1315 REAYSPEK-------HQELGGLPKLYLDGPFGEGHQEWTDFEVSVLVGAGIGVTPFASI LKDLVFKSSVK--FKFHCKKV 1385 dmDUOX 1330 RNYFDPCN--------YNPEDQPKIRIEGPFGGGNQDWYKFEVAVMVGGGIGVTPYASI INDLVEGTSTNRYSGVACKKV 1401 CEDUOX 1290 RSELIRSL---------NTGSPFPLIHMKGPYGDGNQEWMDYEVAIMVGAGIGVTPYASTLVDLVQRTSSDSFHRVRCRKV 1361 CSNOX5 488 YQLIREQREEWIRSGSSQSLPGVPVYIDGPYGTPSTHIFESKYAILICAGIGVTPFASILKS ILHRNQQN-PAKMPLKKV 566

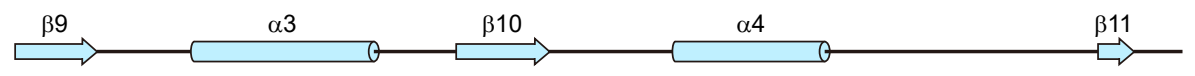

hDUOX1 1418 YFIWVTRTQRQFEWLADIIREVEENDHQDLVSVHIYITQLAEKFDLRTTMLYICERHFQKVL-NRSLFTGLRSITHFGRP 1496 hDUOX2 1415 YFIWVTRTQRQFEWLADI IQEVEENDHQDLVSVHIYVTQLAEKFDLRTTMLYICERHFQKVL-NRSLFTGLRSITHFGRP 1493 drDUOX 1386 YFLWVTRTQRQFEWLSDIIREVEDMDMQDLVSVHIYITQLPEKFDLRTTMLYVCERHFQKVW-NRSLFTGLRSVTHFGRP 1464 dmDUOX 1402 YFLWICPSHKHFEWFIDVLRDVEKKDVTNVLEIHIFITQFFHKFDLRTTMLYICENHFQRLS-KTSIFTGLKAVNHFGRP 1480 CEDUOX 1362 YFLWVCSTHKNYEWFVDVLKNVEDQARSGILETHIFVTQTFHKFDLRTTMLYICEKHFRATNSGISMFTGLHAKNHFGRP 1441 CSNOX5 567 H FYWLNREQKAFEWFVELLSKIEAEDTNNLFDLNLYLTGAQQKSDMKSSTLFVAMDLMHQET-KVDLITGLKSRTKTGRP 645

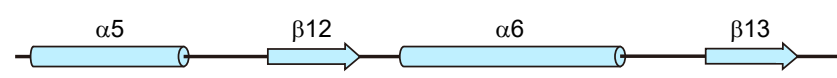

hDUOX1 1497 PFEPFFNSLQEVHPQVRKIGVFSCGPPGMTKNVEKACQLINRQ-DRTHFSHHYENF- 1551 hDUOX2 1494 PFEPFFNSLQEVHPQVRKIGVFSCGPPGMTKNVEKACQLVNRQ-DRAHFMHHYENF- 1548 drDUOX 1465 PFLAFLSSLQEVHPEVEKVGVFSCGPPGLTKNVEKACQQMNKR-DQTHFVHHYENF- 1519 dmDUOX 1481 DMSSELKFVQKKHSYVSKIGVFSCGPRPLTKSVMSACDEVNKTRKLPYFIHHFENFG 1537

CEDUOX 1442 NFKAFFQFIQSEHKEQSKIGVFSCGPVNLNESIAEGCADANRQRDAPSFAHRFETF- 1497 CSNOX5 646 DWEEIFKDVAKQHAP-DNVEVFFCGPTGLALQLRHLCTKYG-------EGYRKENF- 693 
bioRxiv preprint doi: https://doi.org/10.1101/2020.09.23.309245; this version posted September 23, 2020. The copyright holder for this preprint (which was not certified by peer review) is the author/funder, who has granted bioRxiv a license to display the preprint in perpetuity. It is made available under aCC-BY-NC-ND 4.0 International license.

\section{DUOXA}

TM1

TM2

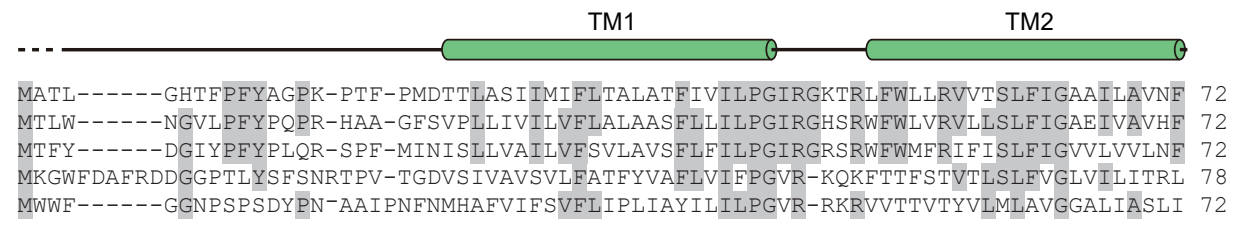

hDUOXA1 1 MATL------GHTFPFYAGPK-PTF-PMDTTLASIIMIFLTALATFIVILPGIRGKTRLFWLLRVVTSLFIGAAILAVNF 72 hDUOXA2 1 MTLW------NGVLPFYPQPR-HAA-GFSVPLLIVILVFLALAASFLLILPGIRGHSRWFWLVRVLLSLFIGAEIVAVHF 72 drDUOXA2 1 MTFY------DGIYPFYPLQR-SPF-MINISLLVAILVESVLAVSFLFI LPGIRGRSRWFWMFRIFISLFIGVVLVVLNF 72 dmDUOXA 1 MKGWFDAFRDDGGPTLYSFSNRTPV-TGDVSIVAVSVLFATFYVAFLVIFPGVR-KOKFTTFSTVTLSLFVGLVILITRL 78 CeDUOXA1 1 MWWF------GGNPSPSDYPN-AAI PNFNMHAFVIFSVFLIPLIAYILILPGVR-RKRVVTTVTYVLMLAVGGALIASLI 72

$\longrightarrow$

hDUOXA1 73 SSEWSVGQVSTNTSYKAFSSEWISADIGLQVGLGGVNITLTGTPVQQLN---------ETINYNEEFTWRLGENYAEEYAK 144 hDUOXA2 73 SAEWFVGTVNTNTSYKAFSAARVTARVRLLVGLEGINITLTGTPVHQLN--------ETIDYNEQFTWRLKENYAAEYAN 144 drDUOXA2 73 TGDWAEARVKANTTYKSFSTAVVSAEVGLHVGLYGINITLKGEPVTQIN--------ETINYNEIISWSS--SVDEQYGD 142 dmDUOXA 79 GSAWHVAHATIIAPYKAFSREKLPARIGTHIGLMHVNVTLTAIPIGNWTP-------PDIDYNERFTWEGANDMSANYRH 151 CEDUOXA1 73 YPCWASGSQMIYTQFRGHSNERILAKIGVEIGLQKVNVTLKFERLLSSNDVLPGSDMTELYYNEGEDISGISSMAEALHH 152

$\alpha 2$

TM3

TM4

hDUOXA1 145 ALEKGLPDPVLYLAEKFTPRSPCG-LYRQYRLAGHYTSAMLWVAFLCWLIANVMLSMPVLVYGGYMLLATGIFQLLALLF 223 hDUOXA2 145 ALEKGLPDPVLYLAEKFTPSSPCG-LYHQYHLAGHYASATLWVAFCFLLSNVLLSTPAPLYGGLALLTTGAFALFGV-- 221 drDUOXA2 143 ALERGLPNPILYIAEKFTYNSACG-LIYQYSYSARFASANLWTAFCCWLLANILFSMPVILYAGYMMIATAAFIFFSVAS 221 dmDUOXA 152 ALQRGLPFPILTVAEYFSLGREGFSWGGQYRAAGYFASIMLWASLASWLLMNLLL-IAVPRYGAYMKALTGALLVCTTVG 230 ceDUOXA1 153 GLENGLPYPMLSVLEYFSLNQDSFDWGRHYRVAGHYTHAAIWFAFACWCLSVVLM-LFLPHNAYKS ILATGISCLIACLV 231

TM5

hDUOXA1 224 FSMATSLTSP----CPLHLGASVLHTHHGPAFWITLTTGLLCVLLGLAMAVAHRMQPHRLKAFFN----QSVDEDPMLEW 295 hDUOXA2 222 FALASISSVPL---CPLRLGSSALTTQYGAAFWVTLATGVLCLFLGGAVVSLQYVRPSALRTLLD----QSAK-----DC 289 drDUOXA2 222 FSTIYNV-SP----CDFSIGSEALRTDYSHSFWLALATGLLCAVIGLLVVLLDCLFPARMREAFS----VGVDDED---- 288 dmDUOXA 231 YHCLLPK-RP----LSIHLEGGRLEFHFGWCYWLVLVAGILCFIAGVLISIIDLVWPHTFSTVLEVYYGTPYDRHVILEE 305 CEDUOXA1 232 YLLLSPC-ELRIAFTGENFERVDLTATFSFCFYLIFAIGILCVLCGLGLGICEHWRIYTLSTFLD----ASLDEHVGPKW 306 
bioRxiv preprint doi: https://doi.org/10.1101/2020.09.23.309245; this version posted September 23, 2020. The copyright holder for this preprint (which was not certified by peer review) is the author/funder, who has granted bioRxiv a license to display the preprint in perpetuity. It is made available under aCC-BY-NC-ND 4.0 International license.

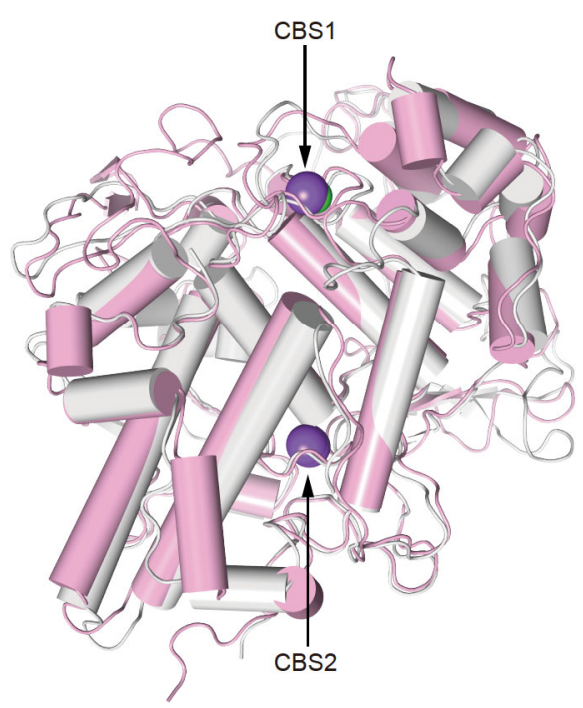

b
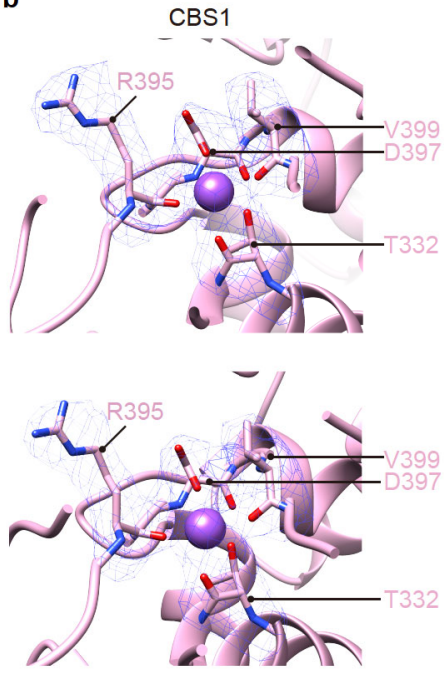

C

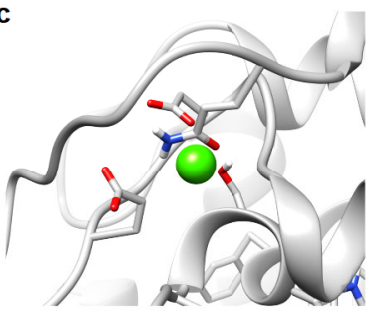

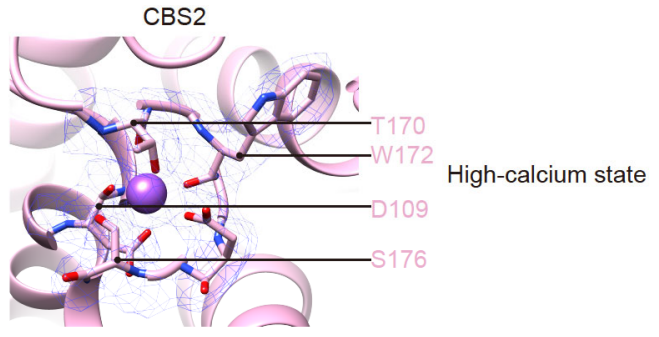
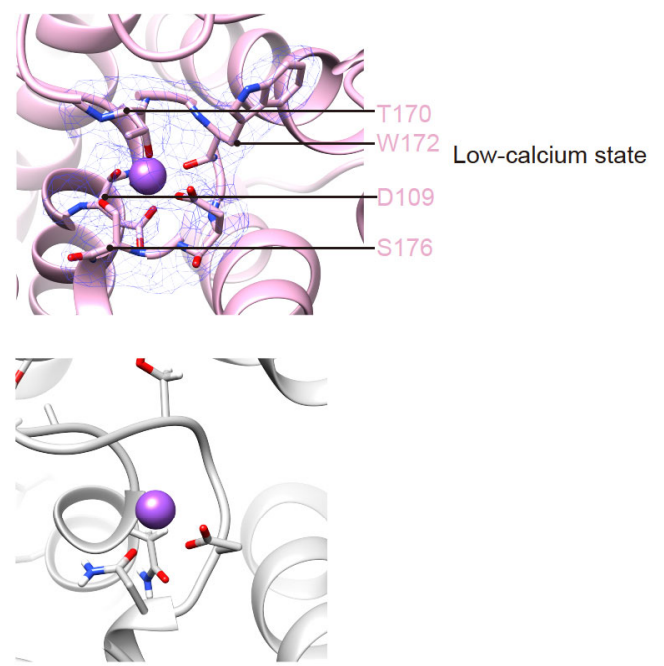

6ERC CBS2

d
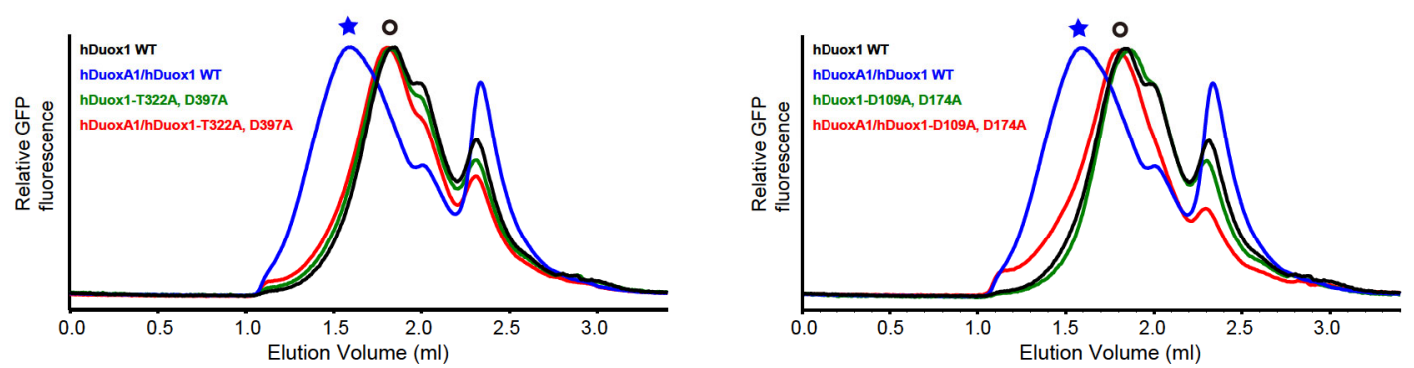

Fig. 59 
bioRxiv preprint doi: https://doi.org/10.1101/2020.09.23.309245; this version posted September 23, 2020. The copyright holder for this preprint (which was not certified by peer review) is the author/funder, who has granted bioRxiv a license to display the preprint in perpetuity. It is made available under aCC-BY-NC-ND 4.0 International license.

a

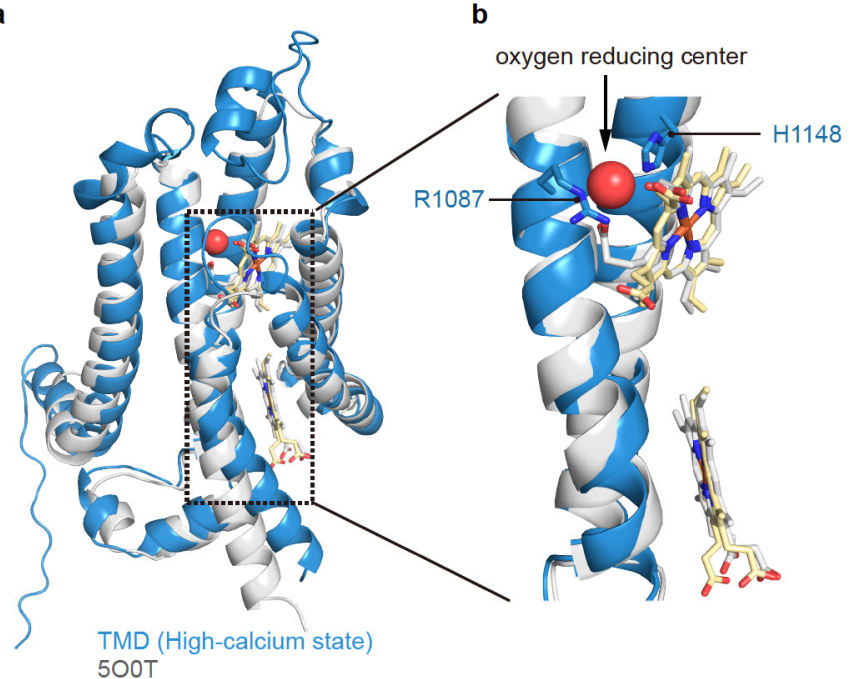

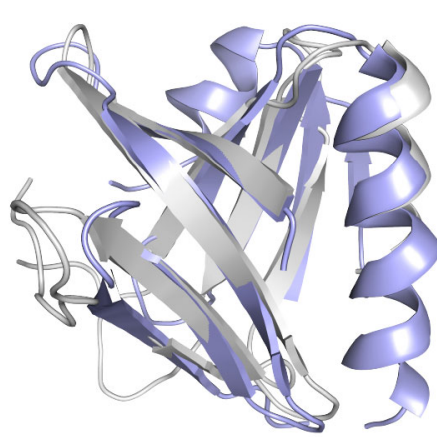

PHLD (High-calcium state) $3 \mathrm{KZ1}$ d

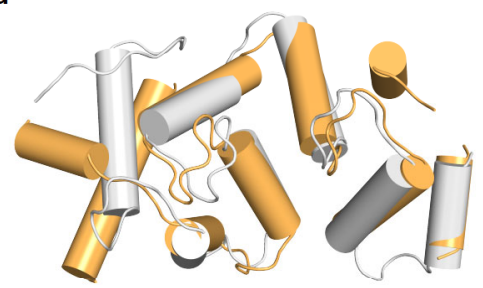

EF12 (High-calcium state) 4IL1 e

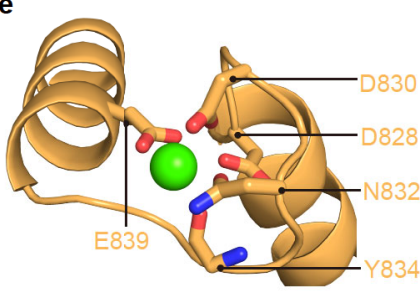

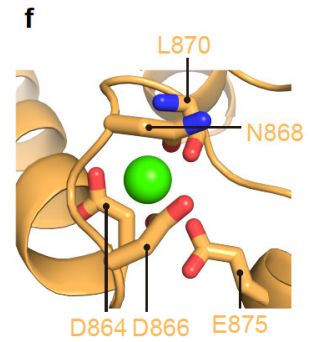

g

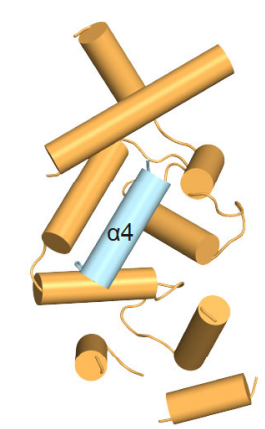

EF12-DH (High-calcium state) h

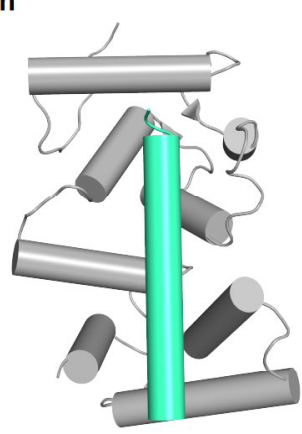

i

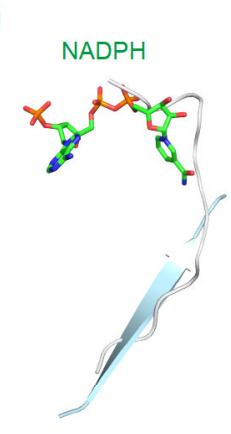

DH $C$ terminal $\beta 13$

$500 \times \mathrm{C}$ terminal loop j Adenosine group Adenosine group

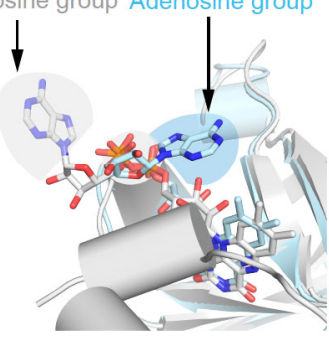

hDuox FAD 5O0X-FAD

Fig. $\mathbf{S 1 0}$ 
bioRxiv preprint doi: https://doi.org/10.1101/2020.09.23.309245; this version posted September 23, 2020. The copyright holder for this preprint (which was not certified by peer review) is the author/funder, who has granted bioRxiv a license to display the preprint in perpetuity. It is made available under aCC-BY-NC-ND 4.0 International license.

a

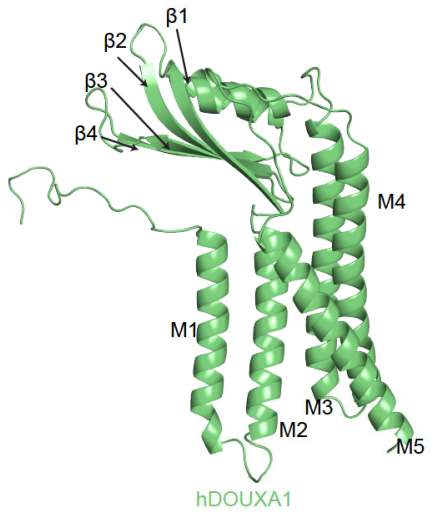

b

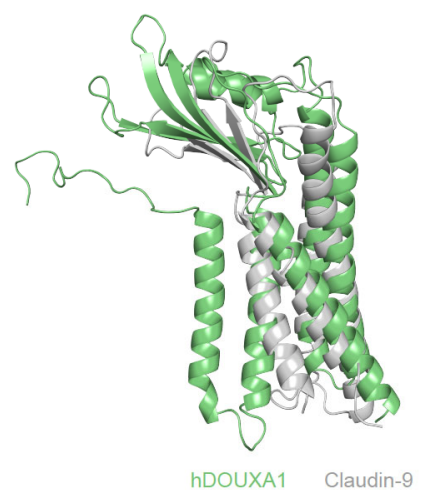

Fig. S11 


\section{Table. S1}

\section{Cryo-EM data collection, refinement and validation statistics}

\begin{tabular}{|c|c|c|}
\hline $\begin{array}{l}\text { PDB ID } \\
\text { EMDB ID }\end{array}$ & $\begin{array}{c}\text { High-calcium state } \\
\text { 7D3F } \\
\text { EMD-30556 }\end{array}$ & $\begin{array}{c}\text { Low-calcium state } \\
\text { 7D3E } \\
\text { EMD-30555 }\end{array}$ \\
\hline \multicolumn{3}{|l|}{$\begin{array}{l}\text { Data collection and } \\
\text { processing }\end{array}$} \\
\hline Magnification & $130,000 \times$ & $130,000 \times$ \\
\hline Voltage $(\mathrm{kV})$ & 300 & 300 \\
\hline Electron exposure $\left(\mathrm{e}-/ \AA^{2}\right)$ & 50 & 50 \\
\hline Defocus range $(\mu \mathrm{m})$ & -1.5 to -2.0 & -1.5 to -2.0 \\
\hline Pixel size $(\AA)$ & 1.045 & 1.045 \\
\hline Symmetry imposed & C2 & $C 2$ \\
\hline Initial particle images (no.) & $1,043,262$ & 783,802 \\
\hline Final particle images (no.) & 372,815 & 125,984 \\
\hline Map resolution $(\AA)$ & $2.6(2.5 / 3.2)^{*}$ & $2.7(2.8 / 3.4)^{*}$ \\
\hline FSC threshold & 0.143 & 0.143 \\
\hline Map resolution range $(\AA)$ & $250.0-2.5$ & $250.0-2.8$ \\
\hline \multicolumn{3}{|l|}{ Refinement } \\
\hline Initial model used (PDB code) & \multicolumn{2}{|c|}{ 6ERC, 5O0T, 4IL1, 5O0X } \\
\hline Model resolution $(\AA)$ & 2.5 & 2.8 \\
\hline FSC threshold & 0.5 & 0.5 \\
\hline Model resolution range $(\AA)$ & $250.0-2.5$ & $250.0-2.8$ \\
\hline Map sharpening $B$ factor $\left(\AA^{2}\right)$ & $(-98.1 /-153.3)^{*}$ & $(-76.0 /-122.2)^{*}$ \\
\hline \multicolumn{3}{|l|}{ Model composition } \\
\hline Non-hydrogen atoms & 26,516 & 26,012 \\
\hline Protein residues & 3,284 & 3,304 \\
\hline Ligands & 46 & 42 \\
\hline Water & 2 & 2 \\
\hline$B$ factors $\left(\AA^{2}\right)$ & 67.59 & 84.85 \\
\hline Protein & 67.82 & 84.95 \\
\hline Ligand & 59.61 & 81.66 \\
\hline Water & 52.99 & 76.84 \\
\hline \multicolumn{3}{|l|}{ R.m.s. deviations } \\
\hline Bond lengths $(\AA)$ & 0.008 & 0.011 \\
\hline Bond angles $\left(^{\circ}\right)$ & 1.258 & 1.212 \\
\hline \multicolumn{3}{|l|}{ Validation } \\
\hline MolProbity score & 2.08 & 1.89 \\
\hline Clashscore & 13.06 & 12.78 \\
\hline Poor rotamers $(\%)$ & 2.95 & 0.08 \\
\hline \multicolumn{3}{|l|}{ Ramachandran plot } \\
\hline Favored (\%) & 97.53 & 96.07 \\
\hline Allowed (\%) & 2.41 & 3.93 \\
\hline Disallowed (\%) & 0.06 & 0.00 \\
\hline
\end{tabular}

* The numbers outside the brackets are from the consensus refinement. Numbers inside brackets are from the multibody refinement (large body/small body). 